\title{
SPECIFIČNOST DISCIPLINARNIH I INSTITUCIONALNIH PRISTUPA ETNOGRAFSKOM FILMU - MILOVAN GAVAZZI I ANDRIJA ŠTAMPAR
}

U radu se analizira koncepcija etnografskog filma iz rakursa dviju institucija s početka 20. stoljeća: Etnološkog seminara pri Filozofskom fakultetu zagrebačkog Sveučilišta i Škole narodnog zdravlja. Pritom se poseban naglasak u analizi stavlja na etnografičnost filmskih proizvoda dviju različitih institucija koje u svojim filmovima direktno i indirektno reprezentiraju kulturu sela. Raznolika filmska produkcija, nerijetko nekritički svedena pod zajednički nazivnik etnografskog filma, preispitat će se analizom filmskog sadržaja te problematiziranjem naknadnih preispisivanja njihova značenja i recepcije u onodobnom društveno-političkom kontekstu.

Ključne riječi: Milovan Gavazzi, Andrija Štampar, Škola narodnog zdravlja, etnografski film, socijalna medicina, zdravstveno prosvjećivanje

\section{UVOD}

Razvoj etnografskog filma i vizualne antropologije uvelike je ovisio o brzom tehnološkom napretku i dostignućima koja su direktno utjecala na promjene paradigme vizualno-antropoloških teorija s obzirom na nove mogućnosti korištenja filmske opreme na terenu. Inicijalna uloga etnografskog filma kao tehnike bilježenja i zamrzavanja "zbilje" bila je vezana uz postupak dokumentiranja onoga drugog, neobičnog i nestajućeg (spasilačka etnografija) što je najčešće bilo prezentirano kao komplement, odnosno prateća ilustracija pisanim etnografijama, sveučilišnoj nastavi, muzejskim eksponatima ili kao "objektivno" i "istinito" svjedočanstvo odlaska i bivanja na terenu. U prvim takvim vizualnim zapisima glas promatranog subjekta bio je u potpunosti zanemaren, dok su autori filmova imali apsolutnu kontrolu nad onim što (i kako) snimaju i prezentiraju (usp. Urem 2015:25). S vremenom je došlo do promjena u korištenju kamere na terenu, načinu snimanja te u snimljenom materijalu koji je poprimio 
formu samostalnoga filmskog djela koje prenosi određenu ideju, stav ili komentar autora. U skladu s tim, kao i s promjenama tradicije unutar same antropologije, mijenja se uloga proučavanih subjekata ispred objektiva kamere. Prema tome, 'kompleksnost sintagme 'etnografski film' rezultat je interdisciplinarnosti, zaokreta unutar matične discipline, promjena u načinu snimanja i korištenja vizualnog materijala te neujednačenih definicija" (Urem 2015:26). David MacDougall etnografski film ne izjednačava s filmskom etnografijom (1981:6) nego smatra da je etnografski film onaj koji je napravljen kako bi opisao kulturu (ibid.), definirajući ga kao širu kulturnu kategoriju od filmova koji su napravljeni unutar ili za disciplinu antropologije (usp. MacDougall 1998:97-98). Suprotnog je stajališta antropolog vizualne komunikacije Jay Ruby sa svoja četiri kriterija, tvrdeći da etnografski film mora biti temeljen na antropološkim postavkama - teoriji i metodi (Ruby 1975:105), tj. da ga može napraviti samo antropolog/etnolog (usp. Ruby 1975; Gotthardi-Pavlovsky 2009:34). Karl Heider (1976) dosta slično Rubyju pristupa etnografskom filmu i njegovim značajkama, sugerirajući kako su najviše zadovoljavajući oni etnografski filmovi koji razotkrivaju "cijela tijela, i cjelovite narode, u cjelovitim postupcima/radnjama" pružajući tako kulturni i fizički kontekst. Heider je problem definiranja etnografskog filma pokušao riješiti pomoću "etnografičnosti” (usp. Heider 2006:2) čime je označio stupanj uspješnosti filmskog prenošenja etnografskog razumijevanja naroda i djelatnosti koje su prikazane (usp. 1976:97-117, prema Banks 2001:141). Definicija/ definicije etnografskog filma, profesionalni redatelji neantropolozi, odnos vizualne antropologije i njezine matične discipline, balansiranje etnografskih filmova između znanosti i umjetnosti - sve su to pitanja o kojima se kritički polemizira od samih početaka discipline. Debata oko definiranja etnografskih filmova jedna je od najosporavanijih u vizualnoj antropologiji, uključujući i pitanja vezana uz reprezentaciju, autoritet, participaciju, konstrukt, autentičnost, vrijednosti itd., pitanja koja su istaknuta od strane mnogih autora antropologa poput Jamesa Clifforda (usp. 1988, prema Picton 2011:422). Etnografski film najprepoznatljiviji je kao potkategorija dokumentarne filmske tradicije s kojom neminovno dijeli mnoge sličnosti, dok se atribut "etnografski" dodjeljuje uzimajući u obzir produkciju, intenciju ili metodu, ne oslanjajući se isključivo na sadržaj filma (usp. Ruby 2000, prema Durington i Ruby 2011:192). 
Godine rasprava u potrazi za prikladnom definicijom etnografskog filma nisu urodile jedinstvenom definicijom na koju se svi autori ili festivalski selektori mogu pozvati. Ali, upravo ta nemogućnost strogog i preciznog definiranja omogućila je brz i dinamičan razvoj poddiscipline, kao i njezinu raširenost i prisutnost izvan strogo akademsko-znanstvenog područja (usp. Urem 2015:62). Vizualna antropologija nastoji naučiti antropologe da film promatraju kao kulturnu reprezentaciju, umjesto da mu pristupaju isključivo kao dokumentu koji je "znanstveno pouzdan" izvor etnografskih podataka koji izostavlja ulogu i utjecaj samog autora (usp. Puljar D'Alessio 2002:40).

Propitivati sintagmu etnografski film na primjeru filmova Škole narodnog zdravlja ${ }^{1}$ nije moguće bez uvida u kompleksnost društvenih, kulturnih, političkih, institucionalnih i ideoloških okvira koji su omogućili etiketiranje vizualnih zapisa kao etnografskih. Paradoksalnost ovakvog inače uobičajenoga istraživačkog pristupa očituje se u tome što filmovi poput onih ŠNZ-a prvotno nisu smatrani etnografskim filmovima. Štoviše, u gotovo isto vrijeme u kojem nastaju filmovi ŠNZ-a snimani su filmski zapisi prilikom terenskih istraživanja Milovana Gavazzija ${ }^{2}$ u režiji tada novoosnovanog studija etnologije. ${ }^{3}$ Filmski zapisi koje Gavazzi označava pojmom etnološkog filma bi se odabirom scena, porukom i sadržajem neopreznom promatraču činili vrlo slični filmovima ŠNZ-a. U ovom članku prikazat će se djelovanje različitih institucija koje su dvadesetih godina 20. stoljeća stvarale i koristile filmove koji su naknadno zadobivali različite etikete, među njima i navedenu etnografski film. Usporedba i analiza produkcije vizualnih prikaza dviju institucija poput Etnološkog seminara pri Filozofskom fakultetu zagrebačkog Sveučilišta i Škole narodnog zdravlja te svrha korištenja kamere njihovih najistaknutijih predstavnika različitih disciplinarnih polazišta (Milovana Gavazzija i

${ }^{1}$ U daljnjem tekstu ŠNZ ili Škola.

2 Milovan Gavazzi je 1930. godine počeo snimati kamerom, fasciniran novim medijem koji pojavnost može vizualno bilježiti, i to u njezinu kretanju (usp. Križnar 1992:187).

${ }^{3}$ Godine 1927. Milovan Gavazzi napušta posao muzealca i prelazi na Filozofski fakultet zagrebačkog Sveučilišta kako bi predavao na studiju etnologije pri Etnološkom seminaru, danas Odsjek za etnologiju i kulturnu antropologiju (usp. Gotthardi-Pavlovsky 2009:27). 
Andrije Štampara) ima za namjeru uputiti na međuodnos dviju institucija koje su vizualne zapise proizvodile gotovo istodobno $\mathrm{u}$ vrijeme kada je malo tko imao kameru. Nastojat će se upozoriti na genezu sintagme etnografski film u filmovima ŠNZ-a, njihovu povijesnu i društvenu anatomiju i institucionalna određenja. Filmovi ŠNZ-a, čiji etnološki relevantan sadržaj evocira njihovo naknadno žanrovsko određenje i etiketiranje sintagmom etnografski film, promatraju se kao dokumenti kulture i vremena koji transcendentiraju svoju prvotnu namjenu postajući odrazom novijih vremena.

\section{ETNOGRAFSKI FILM PREMA MILOVANU GAVAZZIJU}

U hrvatskoj kinematografiji, konkretnije u počecima eksperimentiranja s etnografskim filmom, vodeću ulogu imao je etnolog Milovan Gavazzi. S obzirom na to da nije raspolagao s dovoljno filmske opreme, njegovi pokušaji bilježenja kulturnih posebnosti bili su određeni selekcijom onoga što namjerava snimiti prije samog čina snimanja. Filmska djelatnost Milovana Gavazzija započinje tridesetih godina 20. stoljeća kada kao etnolog upotrebljava netonsku amatersku kameru istražujući kulturu vlastite zemlje u skladu sa svojim znanstvenim interesima i stavovima (usp. Gotthardi-Pavlovsky 2009:34). Snimao je sve što je pobuđivalo njegov interes, odnosno sve ono što je smatrao otklonom od uobičajene građanske svakodnevice. Dijelove koje je smatrao normalnima, jasnima i za etnologiju nerelevantnima, ostavljao je kao nepopunjene praznine. Gavazzijev "teorijski postulat - sve što je različito unutar seljačke kulture to je vjerojatno i staro - prati konstrukt seljaštva kao nepromjenjive kategorije u kojoj je očuvana stara tradicija" (HR-HDA-1029 [4]). U vrijeme u kojem je tradicijska kultura na selu doživljavala korjenite promjene, Gavazzijeva kamera bilježi pojedine segmente tradicijske kulture Hrvatske koja nestaje ili je pred nestankom iz svakodnevnog života i prakse. Ograničavajući se isključivo na fizičku pojavnost teme koju bilježi, segmente kulture proučavao je izdvojeno od sinkrone socijalne strukture, koje je u skladu s kulturnopovijesnom paradigmom komparirao sa srodnim primjerima iz južnoslavenskih i euroazijskih prostora ne bi li tako došao do onih najstarijih slojeva kulture 
i ustanovio što je čemu podrijetlo. Gavazzi snima filmove, odnosno filmske zapise, sukladno s uvjerenjima Seljačke sloge (usp. Pletenac 1996) pokušavajući kamerom spasiti, prije nego iščezne, kulturu koja nestaje. Tradicijska kultura ${ }^{4}$ predstavlja politički lajtmotiv u vrijeme pokušaja ili priželjkivanja stvaranja nacionalnih država europskih naroda s obzirom na to da je upravo ona to po čemu se razlikujemo od drugih i unutar čega možemo pronaći nužne nacionalne simbole. Međutim, tradicijska je kultura konstrukt jer je uvijek riječ o selektivnim i idealiziranim elementima kulture koji se mijenjaju i prilagođavaju novim okolnostima što vodi do stvaranja i konstruiranja neke nove tradicije koja se poziva na svoju povijesnu autentičnost bez stvaranja vidljivog odmaka od "izvorne tradicije". Unatoč tomu, tradicijska se kultura "uvijek prikazuje kao totalna i autentična, kao značajna istina o prošlosti” (Lass 1988:457, prema Rihtman-Auguštin 1992:26) iako je riječ o drugoj i posredovanoj egzistenciji njezinih elemenata koji dobivaju novu ulogu (usp. RihtmanAuguštin 1978:21). To je bio više nego dovoljan razlog za njezinu zaštitu prije nego što sasvim nestane, odnosno prije nego se transformira u neke nove oblike (usp. Gotthardi-Pavlovsky 2009:31-32). Selekcija scena pokazuje nam konstruktivnost njegovih filmskih zapisa bez obzira na to što se u velikom dijelu svoga opusa strogo pridržavao propisa Instituta za znanstveni film (Institut für wissenschaftlichen Film, IWF, Göttingen),

4 Iako je problem sintagme "tradicijska kultura" unutar antropološkog diskursa problematiziran, relativiziran i dekonstruiran, u ovom se radu navedenoj sintagmi pristupa kao pojmu ruralne kulture koji označava prijenos elemenata iz jedne kulture u drugu kao indikatore nekog oblika reprezentacije. "Tradicijska kultura" evocira upravo onu kulturu koja se povezuje s predmodernim i predindustrijskim društvima što je određuje kao izvornu i tradicionalnu. Svoje reprezentativne oblike i elemente koristi kao nositelje nacionalnog identiteta. Djelatnost Seljačke sloge u međuratnom razdoblju na selu uključivala je i kulturne akcije koje su se zasnivale na postojećoj tradicionalnoj kulturi sa snažnom političkom funkcijom. Suština političke funkcije proizlazila je iz “zadržavanja kulturnog programa na isključivo konzervativnom poimanju seljačke kulture i na dosta izrazitoj nacionalnoj isključivosti" vidljivoj u istraživanjima početaka narodne kulture kada su se beskompromisno odbacivale "posudbe", "inzistirajući na izvornosti kulture koja se razvija u zabitnim selima, u područjima nedostupnima 'tuđoj' civilizaciji - čuvarima 'nacionalnoga' kulturnoga bića” (usp. Rihtman-Auguštin 1979:11-12). 
inzistirajući na znanstvenosti filmskog dokumenta. ${ }^{5}$ Filmovi čije je snimanje bilo dogovoreno s osobljem spomenutog Instituta morali su biti "naglašeno znanstveni", "apsolutni dokument, ne propaganda ili slično" (Križnar 1992:190).

U Gavazzijevu principu rada u kontekstu novoga filmskog medija posebno se može istaknuti njegova oduševljenost pojavom i dostupnošću novog medija koji može vizualno bilježiti pojavnost ${ }^{6}$ i na taj način upotpuniti onaj dio zabilježen tekstualno ili fotografijom. Motivi Gavazzijeva rada s kamerom, odnosno spasilačko bilježenje kulture koja nestaje, neizbježno su formirali zapisivački stil njegova snimanja. Vjekoslav Majcen također konstatira kako Gavazzi evidentno radi filmske zapise, uspoređujući njegove uratke s Flahertyjevima ${ }^{7}$ iz 1930-ih, kao i s onima Jeana Roucha ${ }^{8}$ iz 1950-ih koji su Gavazziju bili uzorom:

5 Njemački antropolozi naglašavali su znanstvenu dimenziju snimanja filma te su uspostavili kodekse čistoće znanstvenoga u filmu. Godine 1959. izdali su Rules for Film Documentation in Ethnology and Folklore. Naglasak su stavili na antropološku komponentu u filmu, na snimanje autentičnih događaja bez upotrebe dramatičnih kutova snimanja i kretanja kamere, a montažu su izbjegavali ili su je koristili s ciljem reprezentativnosti materijala (usp. El Guindi 1998:465).

${ }^{6}$ Gavazzi je bio limitiran na malu netonsku amatersku Agfa movex kameru, što znači da nije mogao njome snimati zvuk, tj. ako je i mogao snimiti zvuk nekim drugim sredstvom, nije ga mogao sinkronizirati s pripadajućom mu slikom. To je rezultiralo nijemim filmskim zapisima. U kasetu je mogao staviti samo 12 metara filma, pa je često morao prekidati snimanje zbog njezina mijenjanja, što znači da nije mogao snimati događaje i radnje u njihovu realnom kontinuitetu (usp. Križnar 1992:187).

7 Robert Joseph Flaherty rođen je 1884. godine u Iron Mountainu (Michigan, SAD). U područje zaljeva Hudson odlazi već 1910. godine provodeći istraživanja za rudarsku kompaniju. Nakon toga uslijedile su tri ekspedicije na kojima je započeo sa snimanjem inuitske zajednice koja je naseljavala spomenuto područje. Međutim, nesretnim slučajem ostao je bez snimljenog materijala te 1921. godine odlazi na četvrtu ekspediciju kako bi iznova snimio filmski materijal. Iako je Flaherty prije svega bio istraživač i mineralog, 1922. godine izašao je njegov filmski uradak Nanook sa sjevera (Nanook of the North) koji je ostvario velik međunarodni uspjeh u kinodvoranama. Navedenim filmom Flaherty je afirmirao svoju poziciju u filmskoj industriji, dok se ubrzo u stručnoj literaturi njegovo ime počelo uvrštavati među pionire dokumentarnog filma (usp. Engelbrecht 2007:467-468). Također, Flaherty se može smatrati prvim sineastom koji je koristio participacijskoopservacijski model dokumentarnog filma (usp. Nichols 2001:168-177) što je vidljivo u Nanooku sa sjevera koji prikazuje dnevne aktivnosti kanadske inuitske zajednice gradeći “egzotičnu, a opet dovoljno prihvatljivu sliku Drugoga” (Borjan 2013a:83). 
"Gavazzi nije imao želje realizirati slične složene filmske projekte. Njegovo zanimanje za film čvrsto je bilo ograničeno na egzaktno [odnosno, za ono vrijeme znanstveno - jer, da bi bilo znanstveno, mora biti egzaktno, op. a.] vizualno bilježenje određene pojave." (Majcen 1998b:166)

Uostalom, svoju primarnu namjeru dokumentiranja navodi i sam Gavazzi: "I tako je pala ideja da se bar ono što pokretno, da se to bar filmski snimi kao dokument" (Križnar 1992:187). Kasnije, 1960-ih, Gavazzi predlaže podjelu etnografskih filmskih uradaka na rodove, među kojima navodi i "kinematografsko-etnografsko-folklorne beležke" koje je i sam radio (Gavazzi 1987:112). Filmu je u kontekstu svoga znanstvenog rada davao isključivo pomoćnu ulogu kao "pomagalo koje je u prvom redu bilo namijenjeno studentima etnologije i stručnjacima koji proučavaju tradicije, [...] da vide u stvari kako se nešto kreće [...] što inače drugim sredstvima nije moguće" (Križnar 1992:189). U svojim rijetkim pismeno zabilježenim razmišljanjima o filmu Gavazzi je napisao kako je riječ o

"novijoj oznaci proizašloj iz potrebe da se kratkim izrazom označi jedna grana (žanr) filma, koja se na neki način 'iskristalizirala' kroz dulje vrijeme tražeći zasebnu oznaku i mjesto, napose u okviru dokumentarnog stručnog, odnosno naučnog filma." (Gavazzi 1964:57)

8 Jean Rouch rođen je u Parizu 1917. godine. Radeći kao građevinski inženjer u Nigeru gdje je prvi put otišao 1941., Rouch se sve više počeo zanimati za rituale lokalnog stanovništva (trans, obredi opsjednutosti, tradicionalne ceremonije i svakodnevni život), provodeći terenska istraživanja koja su rezultirala etnografskim esejima i filmovima. Prije snimanja svojih prvih filmova, Rouch je u Francuskoj završio studij antropologije. Za povijest etnografskog filma značajan je zbog eksperimentiranja s filmskim jezikom poigravajući se s konvencijama fikcionalnog i nefikcionalnog filma (ethno-fiction) te kao začetnik kolaborativnog pristupa, refleksivnog filma i filma istine (cinema vérité ujedinjenost ideja sovjetskog redatelja Dzige Vertova i Roberta Flahertyja). S obzirom na avangardne poteze u svojim filmskim uracima, zamjenjujući "objektivni distancirani pogled polufikcionalnom konstrukcijom zbilje", Rouchovi filmovi nisu bili objeručke prihvaćeni među antropolozima (usp. Borjan 2013a:101-123; Durington i Ruby 2011:198; Engelbrecht 2007:477-478). 
Početke etnografskog filma Gavazzi smješta daleko u prošlost, u vrijeme nastanka poučnih filmova o stranim zemljama i njihovim domorocima (usp. ibid). Takvi filmovi imali su status filmskih zapisa koji su, baš poput teksta, imali snagu tekstualnih bilježaka.

Unatoč njegovu skromnom pisanom doprinosu i inzistiranju na proizvodnji znanstvenih filmova, Gavazzi je bio svjestan problematike smještanja etnografskog filma unutar znanstvenog diskursa, odnosno (ne) prihvaćanja njegove znanstvene relevantnosti i vrijednosti. Posljedica ovakvog odnosa prema filmu prije svega se manifestira neravnopravnošću etnografskog filma i pisane etnografije. Gavazzi je također svjestan problema definiranja etnografskog filma kao dokumenta, relevantnog i upotrebljivog u znanstvene svrhe jer

"da je etnografski film - pretpostavljeno stručno valjan i vjeran i tehnički bez prigovora - naučni dokument, o tome jamačno ne bi trebalo trošiti riječi. Tako se danas sa dna arhiva izvlače filmske snimke prije pedesetak godina, koje često čuvaju živu sliku onoga, čemu danas više nema ni traga. Iz tih filmova se probire ono što je filmski bolje i ostvaruju se takvim prastarim materijalom novi filmovi, katkad za naučne svrhe prvorazredne važnosti." (Gavazzi 1964:58)

Nadalje, Gavazzi u odnos stavlja filmski dokument prema zbiljskom konkretnom toku i trajanju nekog zbivanja etnografskog značaja

“jer je etnografski film nužno ponajviše skraćenje realnog zbivanja, što nameće samo po sebi izbor etnološki najznačajnijih 'isječaka' iz dulje cjeline snimanog zbivanja (a to izaziva i pitanje: koja su 'najznačajnija'!...), on je 'istrgan' - kao uostalom i fotografija - iz nekoga mnogo širega konteksta kulture, u kojoj je zahvaćen itd." (ibid. 59)

Gavazzi je prethodnim rečenicama obrazložio na koji se način koriste starije etnografske snimke za koje i dalje tvrdi da predstavljaju i čuvaju "živu sliku onoga, čemu danas više nema ni traga", upozoravajući tako na prvotnu funkciju etnografskog filma kao vizualnog svjedočanstva koje ima očuvati ili generirati trajne slike (usp. ibid. 58). Danas je ovakav pristup podvrgnut kritici s obzirom na to da je očigledno kako jedna takva 
snimka nije lišena sklonosti samog autora (njegovih interesa i namjera) i okolnosti u kojima je nastala. Snimka čuva jednu sliku, jednog autora i jedan trenutak pa danas kada ju promatramo, gledamo i vidimo nešto drugo od publike koja ju je promatrala u vrijeme kada je nastala. Također, film kategorizira (i odjeljuje) kao "strogo naučni dokument" i kao "običan dokument kulture" s posebnim naglaskom na obilježja koja odražavaju "vjernost činjenicama i autentičnost u najboljem smislu" (usp. ibid. 59-60). Gavazzi je bio upoznat s metodologijom Flahertyjeva rada na što se i referira u kontekstu rastuće vrijednosti njegovih filmova kao prvorazrednih dokumenata, tvrdeći kako je proizvodnja takvih dokumenata ostvariva uz nužnu neposrednost pri snimanju i minimum režiranja (usp. ibid. 60). Osvrnuo se i na vrijednost filma u nastavi, posebno kao pomagalo u nastavi etnoloških i kulturnoantropoloških kolegija smatrajući film

"najsavršenijim pomagalom kao nadomjestak za zbivanja i činjenice iz stvarnosti koji po svojoj naravnoj privlačnosti za svakoga čovjeka znači moćno sredstvo, koje se može razumno i odmjereno vanredno koristiti i u ovom općeobrazovnom i općeodgojnom smjeru. A njegova se uloga osim toga potencira kao socijalno-pedagoškoga sredstva napose, što je svagda, u većoj ili manjoj mjeri sam po sebi usmjeren prema produbljivanju raspoloženja i smisla za razumijevanje stranih naroda, njihove kulture i načina života, i pače vrlo dalekih, za suosjećanje s njihovim životnim naporima, tegobama, radostima." (ibid. 61-62)

Gavazzi pravi razliku između etnografskog i etnološkog filma. Etnografski, isključivo faktografski film definira kao film s opisnim značajkama koji potpuno vjerno sakuplja i dokumentira činjenice kakve jesu (usp. ibid. 62-63). Riječ je o filmu koji je stvar terenskog etnografa s mnogovrsnom stručnom spremom koja uključuje onu etnološkoetnografsku i fotofilmsku (usp. ibid. 62). Dok etnološki film definira kao znanstveno-planski komponirani film koji promatraču predstavlja određenu već stečenu etnološku spoznaju ili daje na razmatranje neki filmski oblikovani problem (usp. ibid. 62-63). Naglasak je ipak stavljen na etnografski film koji je predstavljen kao rezultat, odnosno proizvod terenskog etnografa. Riječ je o proizvodima koji su plod neodgodive terenske spasilačke etnografije, što najvećim dijelom Gavazzijevi filmski 
zapisi i jesu. Kada imamo vizualni materijal koji nazivamo filmskim zapisom, nikada nismo upoznati s kontekstom snimanja jednoga takvog dokumenta. Prema tome, u kontekstu snimanja zapisa uvijek govorimo o dokumentu danog trenutka. Osim brojnih podudaranja u razmišljanju i djelovanju sa svjetski poznatim autorima i vizualnim antropolozima, najčešće se navodi poredbena važnost koju je pridavao filmovima, poput Margaret Mead (usp. ibid.). Očigledno je Gavazzi bio svjestan filma kao konstrukta, ali uz teško odricanje pojmova poput autentičnosti i izvornosti. Etnografski film može biti neka vrsta neporecivoga znanstvenog arbitra pri kakvom etnološkom problemu ili etnološkoj interpretaciji, tvrdi Gavazzi (usp. ibid. 58). Smatra kako će ti filmovi (odnosno, valjane, nevarljive filmske snimke) moći poslužiti za ispravljanje dosad nepotpunih ili pak krivih predodžbi, stvaranih na osnovi površnih ili nepotpunih, letimičnih motrenja nekoga proizvodnog procesa, običaja ili obreda. Posebno spominje korist filmskih snimaka za posebne potrebe kao što je npr. bolje uočavanje i analiza često brzih kretnja kod plesova, radnih pokreta i sl. koji se mogu postići usporavanjem ili zaustavljanjem pojedinih snimaka samih za promatranje itd. Iz ovih tvrdnji jasan je stav koji zastupa Gavazzi promatrajući i analizirajući filmove kao nepobitne dokaze, vjerujući kako je ono što vidimo i što je moguće više puta gledati, zaustavljati i analizirati, dovoljna i jasna potvrda istinitosti.

Za Gavazzija etnološki film može biti čisti dokument nečega što je bilo (kada govori o rekonstrukciji) ili je još uvijek tu (odnosno, nije rekonstruirano pa može služiti za etnološka istraživanja), ali kao etnološki bolji način ipak ističe komparativni etnološki film (usporedba izrezaka iz nekoliko filmova unutar jednog filma) (usp. Križnar 1992:194). Također drži kako je od velike važnosti da je snimatelj takvih filmova diplomirani etnolog kako bi eventualni propusti prilikom snimanja bili svedeni na minimum jer "opasnost od pogreške mnogo je manja ako čovjek kao gotovi etnolog, pogotovo iskusni etnolog, iskusni filmski snimatelj, sam snima svojom rukom" (ibid. 195). Gavazzi etnografski film definira kao novu oznaku' koja je proizašla iz potrebe označavanja nove filmske grane (žanra), koja se na neki način iskristalizirala kroz dulje vrijeme i tražila zasebnu oznaku i

9 Novu u vrijeme kada je Gavazzijev tekst napisan, 1964. godine. 
mjesto, naročito u okviru dokumentarnoga stručnog, odnosno znanstvenog filma. On također početke etnografskog filma smješta daleko u prošlost filmskih snimanja, vraćajući se sve do filmova poučnog značaja i svrhe o stranim zemljama i njihovim domorocima. Ali, pored nastajanja ovakvih nesistematskih, većinom fragmentarnih filmova etnografskog sadržaja javlja se dosta davno i nastojanje da se pored filmova kao znanstvenih dokumenata različitih znanosti, filmski snimaju mnogobrojna zbivanja iz života i kultura tzv. primitivnih i poluciviliziranih naroda. Ovakav način snimanja Gavazzi označava kao "etnografsko u strogom smislu tog izraza u planski zaokruženim cjelinama značaja naučnog dokumenta" (Gavazzi 1964:57). Gavazzi je isticao vrijednost filmova kao cjelina ne slažući se sa strogim pravilima rada Instituta za znanstveni film u Göttingenu i njihova arhiva Encyclopaedia Cinematographica ${ }^{10}$ koji uzima samo pojedine scene, zasebne cjeline, bez obzira na dugo trajanje pojedinih cjelokupnih običaja - fokusirani su na enciklopedijske jedinice, a ne na filmove (usp. Križnar 1992:195). Ovaj je podatak vrlo zanimljiv s obzirom na to da je Gavazzi surađivao s Institutom prilagođavajući se njihovim strogim kriterijima koji osiguravaju znanstvenost filma, odnosno sekvenci zapisa, kojoj je toliko težio. Iz takvih postupaka dalo se zaključiti da u potpunosti podržava takav način izrade filmova, s obzirom na to da je izradio priličan broj etnografskih zapisa. Prema njegovim kriterijima, gotovo bi sve filmove trebalo promatrati kao etnografske dokumente čija je iskoristivost velika i koji služe u svrhu istraživanja, za prikazivanje studentima u sklopu nastave i sl. (usp. ibid. 196).

Milovana Gavazzija, autora mnogih etnografskih filmskih zapisa, možemo nazvati prvim hrvatskim vizualnim antropologom koji je koncept etnografskog filma ili vizualne antropologije problematizirao tek na samom kraju radnog vijeka komentirajući upravo etnografsko-filmske teme, svoju fascinaciju filmom Nanook sa sjevera (Nanook of the North, 1922.) te divljenje koje je imao prema Jeanu Rouchu i njegovim djelima (usp. Križnar 1992, prema Borjan 2013:13).

\footnotetext{
${ }^{10}$ Suradnja IWF-a i Milovana Gavazzija očitovala se i u dobivenom materijalu za snimanje s kojim je Gavazzi često bio u oskudici. Može se pretpostaviti kako je Gavazzi u mnogim svojim filmskim zapisima slijedio pravila IWF da bi kao znanstveno značajni postali dijelom njihova arhiva.
} 
Prema izvještajima s terena koji se čuvaju u Hrvatskom državnom arhivu u Zagrebu, ${ }^{11}$ vidljivo je kako je Gavazzi vršio pripreme prije samog snimanja kako bi sam postupak na terenu prošao sa što manje nepredviđenih poteškoća. Takva snimanja Gavazzi naziva filmskim dokumentom, koji je to važniji što su prisutnije promjene u suvremenim prilikama. Na primjeru lončarstva u Velom Ižu Gavazzi je istaknuo kako je bio "urgentan zadatak da se ovaj značajan svjedok našega narodnog rukotvorstva za sva vremena sačuva kao filmski dokument." Ovaj nam primjer jasno potvrđuje kako snimanje nikada nije u potpunosti čisti dokument lišen bilo kakva autorova utjecaja. Vjerojatno bi prikladnije bilo govoriti o slici, a ne o dokumentu koji nužno ne spašava primjerice pojedini običaj nego njegovu uhvaćenu sliku stavlja u zadane okvire filmske vrpce ili fotografije, štiteći ga tako od zuba vremena - ono uhvaćeno se ne mijenja, dok se sam običaj koji živi zasigurno i neizbježno mijenja. Sam dokument nije taj konkretni običaj nego dokument predstavlja niz (vizualnih) informacija o običaju kako ga vidi autor (filma). Proizvodnja filmova koji čine fond filmoteke Odsjeka za etnologiju odvijala se u znanstveno-edukacijsko-nastavne svrhe. Vjerojatno je takva svrha bila jedan od razloga Gavazzijeva strogog pridržavanja uputa za što objektivnije i time znanstvenije snimanje filmova, s minimalno uplitanja od strane autora. Takav način snimanja prati teorijske paradigme toga vremena kao i upute IWF-a s kojima Gavazzi surađuje.

Pojava filmova (odnosno filmskih zapisa) koji su dobili prefiks etnografski nimalo nije kasnila za sličnim svjetskim događanjima kada govorimo u kontekstu pojave i razvoja etnografskog filma i vizualne antropologije. Kao što je već istaknuto, nedugo nakon Flahertyjeva Nanooka sa sjevera Hrvatska je dobila svoje prve etnografske filmove (u širem smislu te riječi), poput filma (filmskog zapisa) Seljačka svadba u Hrvatskoj (veljača 1922.) iz nikada realiziranog serijala Narodni život $i$ običaji (usp. Majcen 1995/1996:123; Gotthardi-Pavlovsky 2009:23-24). Razmatrajući stil snimanja Seljačkih svatova iz Sunje (Seljačka svadba u Hrvatskoj drugi je naziv istoga filmskog zapisa), ne možemo govoriti o filmu nego o filmskom zapisu koji izgleda kao čisti dokument, na čemu je

${ }^{11}$ Izvještaj o snimanju etnografskih filmova, br. 10/1964., Zagreb, 1. listopada 1964. (HRHDA-1029 [1]). 
Gavazzi inzistirao pri produkciji svojih (filmskih) zapisa. Okrećući se tako kulturi koja nestaje, radio je filmske zapise - dokumente iz područja seoske tradicijske kulture Hrvatske i Bosne: tehnika lončarstva iz Potravlja kod Sinja i s otoka Iža; ribolov mrežom migavicom s otoka Pašmana, pletenje jalbe; te pogreb na saonicama u Trgu kod Ozlja (usp. Ghottardi-Pavlovsky 2009:32).

Povjesničar filma Vjekoslav Majcen piše kako zapisivački stil određuju kontinuirane snimke dugih, neprekinutih kadrova, bez pomicanja kamere u kadru (osim kraćih panorama) ili promjene udaljenosti s koje se snima, s prekidima koji nastaju tek zbog mijenjanja filmske kasete. Prizori ponovljeni u stvarnosti ponovljeni su i u filmskom zapisu što film približava realnom trajanju promatranog događaja. Najčešće korišten filmski plan zapisivačkog stila jest srednji plan kojim se obuhvaća cijela ljudska figura s neposrednom okolinom u kojoj se odigrava radnja te krupni plan (usp. 1998b:165). S malom kamerom, Gavazzi je bio vrlo pokretan prilikom postupka snimanja (Gavazzi, u Križnar 1992:188), ali vjerojatno je takve kadrove smatrao etnografičnijima, tj. primjerenijima svrsi koju im je namijenio (usp. Gotthardi-Pavlovsky 2009:33). Gavazzi je, prema tome, snimao nešto što je bolje ne nazivati filmovima, pogotovo ako se držimo definicije koju iznosi Aleksej Gotthardi-Pavlovsky (ibid. 9-10), prema kojoj neko vizualno djelo možemo nazvali filmom ako ono prenosi autorovo stajalište koristeći filmska sredstva (usp. Gotthardi-Pavlovsky 2002/2003). ${ }^{12}$ Gavazzi je najčešće snimao sam, bez (profesionalne) filmske ekipe pa se postavlja pitanje je li njegov samostalan rad bio stvar izbora, nužde ili najvjerojatnije i jednog i drugog. Možemo pretpostaviti kako je, inzistirajući na znanstvenosti filmskog dokumenta/zapisa, izbjegavao prisutnost većeg broja ljudi na lokaciji snimanja kako se ne bi narušila izvornost npr. običaja koji je snimao.

12 Prema Etami Borjan (2013:22), sljedbenici tvrdokorne vizualne antropologije mogu u pitanje dovesti klasifikaciju uradaka nastalih od strane neantropologa koji se, prema autorici, mogu u najširem smislu svrstati u podvrste etnografskog filma. Sve učestalijom primjenom digitalnih medija mijenja se koncept etnografskog filma koji danas nije isključivo vezan uz akademske krugove, prema tome mijenja se i njegov krajnji cilj, namjena, ciljana publika, distribucija i produkcija. 


\section{FILMSKA DJELATNOST ŠKOLE NARODNOG ZDRAVLJA U PRVOJ POLOVINI 20. STOLJEĆA}

U gotovo istom razdoblju, svoj pristup (etnografskom) filmu imali su liječnici i njihovi kolege iz zagrebačke Škole narodnog zdravlja. Njihov etno-filmski pogled na vlastitoga ruralnog Drugog bio je još nadmoćniji od pogleda etnologa. Riječ je o pogledu zdravstvenih djelatnika koji su bili zaprepašteni zatečenim higijenskim, društveno-ekonomskim i medicinskim uvjetima u kojima je živjelo osiromašeno ruralno stanovništvo. Značenje takvog pogleda približava Tanja Bukovčan u svom komentaru gdje navodi kako je "“kolonijalni' karakter njihova pogleda bio znanstven i profesionalan, utemeljen u politici i moći medicinskog sustava" (usp. Borjan 2013:14).

Usporedno s Gavazzijevim prvim filmskim zapisima te razvojem filmskog načina izražavanja i filmske industrije, u Hrvatskoj se tijekom prve polovine 20. stoljeća razvija svijest o učinkovitosti korištenja filma u edukativne i prosvjetiteljske svrhe prije svega iz zdravstveno-prosvjetiteljskih motiva (usp. Gotthardi-Pavlovsky 2009:25). Za razliku od etnoloških filmova koje Gavazzi snima za stručnu publiku te iz pozicije etnologa koji svoj autoritet gradi iz pozicije sveučilišnog profesora, zdravstveno-prosvjetiteljski karakter filmova ŠNZ-a gradi se na autoritetu Andrije Štampara i njegove ideje socijalne medicine. Štamparova fascinacija filmom kao medijem koji je moguće koristiti u svrhu zdravstvenog prosvjećivanja počinje negdje u isto vrijeme Gavazzijeva i Flahertyjeva djelovanja. Filmska djelatnost ŠNZ-a bila je dio javne društvene, obrazovne i kulturne djelatnosti ove ustanove koja je nastajala u specifičnim međuratnim uvjetima, te se ti filmovi mogu promatrati u kontekstu ukupnih društvenih zbivanja i njihovih pojavnih oblika u hrvatskoj kulturi toga doba. Pojavi i razvoju edukativne filmske metraže pogodovao je razvoj socijalne medicine nakon Prvoga svjetskog rata, koja je ponajprije bila usmjerena prema stanovništvu ruralnih i siromašnih krajeva, a poticana Higijenskom organizacijom Društva naroda (usp. Majcen 1998:159-179). Glavnu riječ u proizvodnji edukativno-prosvjetiteljskih filmova na prostoru današnje Hrvatske imao je upravo fotofilmski odjel ŠNZ-a. Paralelu se može povući sa zapažanjima Anne Grimshaw (2001) koja tvrdi kako izvan aktualnih povijesnih tokova nije moguće razumijevanje značajki koje definiraju načela znanstvene etnografije i dokumentarne kinematografije. Na primjeru rada A. R. Radcliffe-Browna i Johna Griersona iz međuratnog razdoblja, Grimshaw 
piše o poticajnoj prosvjetiteljskoj viziji svijeta koja stavlja naglasak na cilj, integraciju, racionalizam i znanje (usp. 2001:58), one značajke koje obilježavaju vrijeme iznimnih promjena i inovacija, prepoznatljivih i u nastanku kinematografije i moderne antropologije (usp. ibid. 16). Filmskim projekcijama nastojalo se što efikasnije provesti i ubrzati higijenskozdravstveno educiranje s ciljem prevencije i iskorjenjivanja pojedinih bolesti (sušice, malarije, dizenterije) i pojava koje negativno djeluju na zdravlje (poput alkoholizma, neodgovornoga spolnog ponašanja i sl.) (usp. GotthardiPavlovsky 2009:26). Škola narodnog zdravlja održavala je predavanja koja su najčešće bila popraćena projekcijama edukativnih filmova. Naime, u međuratnom razdoblju kada su se epidemije širile munjevitom brzinom, trebalo je djelovati što brže i efikasnije, u čemu se najdjelotvornijim pokazao novi medij. Osim toga, film (pokretna slika) je ostavljao mnogo snažniji dojam na gledatelje koji nisu bili informirani o tadašnjima znanstvenim dostignućima. Osim što je bila riječ o tadašnjem svjetskom trendu, i sam Andrija Štampar bio je poklonikom metode edukacije putem filma, o čemu je i pisao (usp. Majcen 1998a:151).

Vrijedna produkcija obrazovnih ali i dokumentarnih i animiranih filmova Škole narodnog zdravlja (1927. - 1960. $)^{13}$ imala je za temeljnu svrhu zdravstveno prosvjećivanje stanovništva. Osim toga, istodobno je doprinijela stvaranju škole hrvatskoga dokumentarnog i animiranog filma. Tradicija snimanja obrazovnih filmova nastavljena je i nakon 1945. godine, a proizvodnja se sustavno odvijala sve do 1985. godine. Na samom početku djelovanja Škole narodnog zdravlja gotovo istodobno nastaju prerade zdravstvenih dokumentarnih inozemnih filmova i samostalni radovi djelatnika Škole (usp. Zebec et al. 1997:32). Prva faza djelovanja fotofilmskog laboratorija Škole ocijenjena je kao faza eksperimentiranja u traženju filmskog izraza u službi higijenske propagande kojim bi pridobili gledatelje. S obzirom na nedostatak zapisa o reakcijama publike na prikazane filmove, iznimno vrijedno priopćenje u svojoj knjizi iznosi

13 U razdoblju od 1927. do 1960. snimljeno je ukupno 165 filmova, a samo od 1927. do 1939. godine Škola je snimila 66 filmova najčešće kategoriziranih kao nastavni i kulturni filmovi o medicinskim, higijenskim i drugim problemima, odnosno kao namjenski zdravstveno-edukativni filmovi (usp. Dugac 2005:155). 
Željko Dugac (2010). U priopćenju se navodi kako je prikazivanje filmova na selu bilo popraćeno brojnim problemima. Naime, seljaci su za vrijeme prikazivanja filmova neprestano upadali različitim dosjetkama i komentarima, a svoju su pozornost rasipali na beznačajne detalje, primjerice izrugujući se kako glumac drži motiku ili kako kopa, dok glavnu poruku najčešće ne bi ni uočili. Takav film za njih nije bio vjerodostojan jer je iskrivljeno prikazivao njihovu svakodnevicu (usp. Branko Cvjetanović - usmeno priopćenje telefonom, u Dugac 2010:128). Urbane manire kazališnih glumaca (prisutnih u prvoj fazi) često su izazivale smijeh pa će u daljnjoj petnaestogodišnjoj fazi dokumentarnog filma, sa seljacima kao glumcima umjesto onih profesionalnih i sa sasvim izmijenjenom filmskom ekipom, nastati novi smjer s najvećim brojem zdravstveno-odgojnih filmova za borbu protiv socijalnih bolesti (usp. ibid. 34). Projekcije, nakon kojih su često uslijedila kraća predavanja, u velikom su broju bile posjećene od strane mještana (usp. Cvetnić 2009:73). Takvom velikom interesu vjerojatno je pridonijela činjenica kako je riječ o novom mediju, o pokretnim slikama koje su gledatelji sa zanimanjem začuđeno promatrali. Projektor kojim su prikazivani filmovi ručno je pokretao kinooperater, dok su filmovi projicirani na razapetu plahtu na zidu sale u Mraclinu. Cvetnić je u svojoj knjizi Mraclin: kak je negda bilo. Mjestopisne i povijesne crtice (2009) prenio i pokoju sličicu sa samih projekcija, navodeći kako su komentari pojedinih scena znali biti zanimljivi i duhoviti pogotovo u slučaju onih gledatelja koji su kasnili u glasnom čitanju međunaslova ili pratećeg teksta (usp. ibid. 74). U tom drugom razdoblju (od 1930. do 1939. godine), Škola je odvojena od Higijenskog zavoda u Zagrebu te je ostala "neposredno podređena Ministarstvu socijalne politike i narodnog zdravlja" (usp. Zebec et al. 1997:42). Rad u Školi u ovom se razdoblju odvijao u prilično izmijenjenima i kriznim gospodarskim uvjetima, a nije izostalo ni teško političko ozračje kao posljedica atentata na Stjepana Radića i zastupnike Hrvatske seljačke stranke ${ }^{14}$ u beogradskoj Skupštini 1929. godine, prerastanje HSS-a u pokret, stalna napetost s Beogradom te ubojstvo kralja Aleksandra 1934. godine (usp. ibid. 43).

${ }^{14}$ Dalje u tekstu HSS. 


\section{SOCIJALNOMEDICINSKI RAD ŠKOLE NARODNOG ZDRAVLJA I POPULARIZACIJA ZNANOSTI U KONTEKSTU MEĐURATNOG RAZDOBLJA}

Prizivanje vremena u kojem je započela filmska produkcija djelomično je moguće ostvariti upoznavanjem sa širim kontekstom. Razdoblje na koje se u ovom članku referiram podudara se $s$ modernizmom ${ }^{15} \mathrm{u}$ širem smislu, a odnosi se na posljednju veliku epohu u društveno-političkoj i kulturnoj povijesti Zapada koja je počela potkraj 18. stoljeća i trajala do nastupa postmodernizma u drugoj polovini 20. stoljeća. ${ }^{16}$ Riječ je o razdoblju koje karakterizira odbacivanje ili inoviranje tradicije u skladu sa specifičnim okolnostima razvoja modernih industrijskih društava. Jedna od definicija koja oslikava modernistička nastojanja odnosi se na društveno progresivni trend misli koji učvršćuje, odnosno potvrđuje moć stvaranja, poboljšavanja, preoblikovanja ljudske okoline od strane samoga ljudskog bića, uz pomoć praktičnih eksperimenata, znanstvenog znanja ili tehnologije. Stoga, bez obzira na (ne)prilike spomenutog razdoblja svjetske povijesti, svakodnevni život nastavio je ići svojim tokom, prilagođavajući se novonastalim okolnostima i mijenjajući ih. Ukorak s ostalim europskim zemljama sveprisutan je dekorativni stil art déco koji obuhvaća velik dio vremena nazvanog jazz age, roaring twenties i swinging twenties zbog sadržaja koji preplavljuju cijeli svijet pa tako ni Zagreb ne ostaje iznimka: jazz-bendovi novog zvuka i novi plesovi, charleston i fasciniranost plesnom glazbom

\footnotetext{
${ }^{15}$ U kontekstu ovog rada termin modernizam koristi se kao referencija na vrijeme, razdoblje, odnosno njegove specifičnosti (usp. Milenković 2007:5). Modernizam kao rezultat društvene diferencijacije i specijalizacije u modernosti široko je prihvaćena definicija koja se najčešće dovodi u vezu s kapitalističkom modernizacijom na Zapadu, poslije 19. stoljeća (usp. Habermas 1981:7, prema Milenković 2007:16). U sociološkoj imaginaciji, modernost odlikuju slom feudalnih i religijskih poredaka u europskim društvima, proces racionalizacije, socioekonomske diferencijacije, urbanizacije i industrijalizacije. U ovom kontekstu, dominantan teorijski projekt jest onaj koji se prepoznaje kao prosvjetiteljstvo, a kojeg predstavlja "univerzalna racionalnost u formi pozitivističke društvene nauke" gdje je društveni život i život pojedinaca oblikovan objektivnim zakonima analogno onima za koje se vjeruje da postoje u svijetu prirode (usp. Coombe 1991:189, prema Milenković 2007:16).

16 http://www.enciklopedija.hr/Natuknica.aspx?ID=41465 (pristup 12. 3. 2014.).
} 
uz gramofon, izbori za Miss i ljepotice kupališta u ljetnoj sezoni, svijet noćnih klubova, kabarea, revija i zvijezda, kao i novija tehnička dostignuća, avion i cepelin, veliki parobrodi i prekooceanska putovanja. ${ }^{17} \mathrm{Na}$ relaciji selo - grad postojale su velike razlike u svakodnevici koja se odvijala na samo desetak kilometara udaljenosti. Dok su stanovnici Zagreba koristili blagodati napretka civilizacije, samo nekoliko kilometara dalje stanovnici ruralnih područja živjeli su u iznimno lošim i nehigijenskim uvjetima, u siromaštvu, slijedeći običaje i navike nekih drugih, iz perspektive grada, prošlih vremena. Širenje prometne i komunikacijske mreže izgradnjom prometnica, a posebice željezničke pruge, omogućilo je bolju prometnu povezanost koja je približila selo gradu (i obratno). Češće veze između sela i grada umanjile su izoliranost sela što je neminovno vodilo većoj otvorenosti prema novim idejama koje su dolazile iz grada i preustroju životnog ritma.

Istodobno, dvadesete i tridesete godine 20. stoljeća obilježene su velikom krizom koja nastupa kao posljedica ratnih stradanja, gospodarskih poteškoća i neimaštine, ideološko-političkih previranja i nesigurnosti te nove militarizacije. Kaotičnost i nesigurnost međuratnog razdoblja u kojoj se svijet zatekao uvelike je utjecala na pojavu brojnih inovacija i razvoj novih tehnologija te na promjene u društvenom uređenju. Nakon nestanka Habsburške Monarhije, Hrvatska ulazi u sastav Kraljevine Srba, Hrvata i Slovenaca, poslije nazvane Kraljevina Jugoslavija. Burni događaji toga vremena ostavili su jasan trag na živote ljudi te na razvoj i organizaciju novog oblika zdravstvene zaštite (usp. Zebec et al. 1997:5). Riječ je o razdoblju koje označavamo kao početak zdravstvenog prosvjećivanja u kojem je iznimno važnu ulogu imala Škola narodnog zdravlja u Zagrebu pod vodstvom Andrije Štampara (zajedno s drugim sestrinskim ustanovama na širem području tadašnje Kraljevine SHS) (usp. Dugac 2010:2). Osnovne Štamparove idejne postavke temeljile su se na idejama socijalne medicine izložene u deset točaka svojevrsnog manifesta, tzv. naše ideologije koji je objavljen u njegovoj knjizi Pet godina socijalno-medicinskog rada $u$ Kraljevini SHS (usp. Dugac 2005a:24-25).

U složenom procesu modernizacije koji je svjetski rat ubrzao, izgubio se dotadašnji poredak vrijednosti, tradicionalna kultura doživljavala

17 http://fuliranje.com/zanimljivo/ (pristup 12. 3. 2014.). 
je snažnu transformaciju, a kriza identiteta je jačala. Kriza se najjače osjećala na selu koje je obuhvaćalo najveći dio hrvatske populacije i u kojem je modernizacija s nizom novina često bila dočekana s velikom sumnjom i odbijanjem. Na gospodarskom planu, proces modernizacije smatrao se odgovornim za osiromašenje sela (usp. Sremec i Nikolić 1941:103-104). U političkom životu uspostavljanje toga narušenog identiteta i izlaska iz krize pokušao je prevladati pokret braće Radića koji je svojim pragmatičnim pristupom, na osnovi izmirenja društvenih suprotnosti staleža, nastojao vratiti seljacima poljuljano samopouzdanje i od seljaka načiniti djelatni društveni, politički i gospodarski subjekt ${ }^{18}$ (usp. Leček 1995:117-118). Potkraj tridesetih godina 20. stoljeća i sam Štampar razvio je suradnju s organizacijama koje su nastale u krilu HSS-a ${ }^{19}$ (usp. Dugac 2010:131-133) što upućuje na tadašnje postojanje vidljive veze HSS-a i ŠNZ-a, koje su koordinirano provodile obrazovanje seljačkog sloja, međusobno se nadopunjujući. Ideje ŠNZ-a ostvarivale su se brže i potpunije korištenjem filmskog medija (usp. Urem 2015:95). Ekonomsko opterećenje obitelji, prirodni prirast stanovništva te smanjenje smrtnosti rođene djece poboljšanjem medicinske infrastrukture, doveli su do agrarne prenapučenosti koja je u tridesetim godinama 20. stoljeća gotovo u cijeloj Hrvatskoj opteretila život ljudi (usp. Bićanić 1940:147-148). Velik su utjecaj imali i povratnici koji su dugogodišnjim radom u drugom kulturnom i gospodarskom miljeu sa sobom donijeli neka nova, moderna razmišljanja i svjetonazore, u mnogočemu oprečna domaćoj seoskoj tradiciji. Prema tome, može se zaključiti kako mobilnost seoskog stanovništva, socijalna diferencijacija i hijerarhija unutar sela, povećanje komercijalizacije i

\footnotetext{
${ }_{18}$ Jedna od metoda koju je koristio tada utjecajan HSS-a kako bi se selo što lakše uključilo u moderno društvo odnosila se na intenzivno "kulturno-prosvjetno djelovanje putem Seljačke sloge, otvaranjem tečajeva za nepismene, predavanjima, osnivanjem pjevačkih zborova, knjižnica, čitaonica i zadruga. U urbanim sredinama to obraćanje korijenima naroda posebno se odrazilo početkom tridesetih godina 20. stoljeća kada se javlja čitav književni pokret okrenut hrvatskom selu [...] i širenje socijalne gradske i seoske tematike u književnim i likovnim djelima. Potiče se i proučava izvorni seljački umjetnički izraz, od narodne umjetnosti do vrjednovanja tradicionalnih oblika upotrebnih predmeta, običaja i načina života“" (Majcen 1996:130).
}

19 Seljačka sloga i Gospodarska sloga. 
sve veća tržišno-gospodarska orijentacija poljoprivrednih imanja vodi prema društvenom procesu promjena u moderan poredak (usp. Grandits 2012:161-164). Velika uloga pripala je seoskim učiteljima koji su svojim djelovanjem utjelovili nacionalni sustav obrazovanja u selu nadopunjujući time lokalnu i obiteljsku akulturaciju te mijenjajući seoska i obiteljska mjerila vrijednosti. Aktivnosti Škole narodnog zdravlja u kojima su značajnu ulogu imali upravo njihovi filmski proizvodi, odnosno programi i projekti koje su djelatnici Škole sa suradnicima provodili u okviru zdravstvenog prosvjećivanja (s ciljem poboljšanja higijenskog i zdravstvenog stanja širokih narodnih slojeva), možemo također pridružiti širem i kompleksnijem procesu modernizacije. Naime, osnovna djelatnost Škole narodnog zdravlja bila je proučavanje i poučavanje naroda, čime je uvelike utjecala na usvajanje modernog shvaćanja zdravlja i bolesti, definiranog od strane dominantnoga medicinskog sustava biomedicine $i$ odgovarajućih koncepata zapadnog svjetonazora koji su u velikoj mjeri i danas prihvaćeni ${ }^{20}$ (usp. Brenko et al. 2001:191-211; Brenko 2005:107). Od svih zastupljenih metoda rada, poput izdavanja zdravstvenoprosvjetnih knjiga, brošura i letaka te održavanja predavanja i tečajeva, centralna propagandna metoda jest prosvjećivanje ${ }^{21}$ putem filma, novog $\mathrm{i}$ atraktivnog medija.

Dvadesetih godina 20. stoljeća u svijetu se mijenjao i socijalni odnos prema samoj znanosti što se kroz njezinu popularizaciju manifestiralo velikim optimizmom i povjerenjem u znanstvene dosege s nadom da će riješiti brojna pitanja vezana uz javno zdravstvo i socijalne probleme. Odnosno, znanosti se pridavala značajna uloga u kontekstu društvenog napretka gospodarskog rasta, masovnoga zdravstvenog obrazovanja i učinkovite zdravstvene i socijalne zaštite koja bi trebala biti na

\footnotetext{
${ }^{20}$ Razvoj stroge racionalno-analitičke metodologije utemeljene na znanosti i tehnologiji imao je veliku ulogu u pronalasku lijekova za niz bolesti koje su smatrane neizlječivima (usp. Babel 2012:128).

${ }^{21} \mathrm{U}$ međuratnom razdoblju zdravstveno prosvjećivanje i zdravstveni odgoj upotrebljavaju se kao sinonimi, a s jednakim se značenjem koriste i oznake zdravstveno poučavanje i zdravstvena propaganda, dok je suvremeno značenje pojma zdravstveno prosvjećivanje znatno suženo (usp. Dugac 2010:2).
} 
raspolaganju svim slojevima društva bez iznimke (usp. Grmek 1958:94). Za postizanje konkretnih rezultata nužna je bila suradnja medicinskog osoblja sa stručnjacima iz drugih polja, kao i s lokalnim vlastima (Dugac 2005a:40). Krilaticom "Partner, ali ne i patron" željela se istaknuti važnost suradnje i aktivnog sudjelovanja onih koje se prosvjećivalo, ali i države na čijem se području program odvija (usp. Dugac 2005a:4). ŠNZ je zauzeo značajno mjesto u preventivnom javnozdravstvenom radu i zdravstvenom prosvjećivanju u Hrvatskoj i šire. Socijalnomedicinske ideje zastupljene u praksi ŠNZ-a ostvarivale su se kroz prezentaciju dobrih i loših primjera higijene filmski zabilježenih u ruralnim područjima (usp. Zebec et al. 1997:20). Odjeljenje za socijalnu medicinu bilo je jedno od deset odjeljenja Higijenskog zavoda ${ }^{22}$ sa Školom narodnog zdravlja. Ono je razvilo vrlo živu aktivnost u dva smjera: s jedne strane predavanja, plakati, letci, filmovi i izložbe u službi socijalne medicine i prosvjećivanja te s druge strane tečajevi u Školi narodnog zdravlja i na selima (usp. Zebec et al. 1997:32). Unutar Odjeljenja za socijalnu medicinu postojala su tri Odsjeka $^{23}$ među kojima i Odsjek za higijensku propagandu čija je zadaća bila održavati pučka predavanja uz vlastita nastavna pomagala (knjige, časopisi, brošure, letci, plakati, filmovi...) (usp. ibid. 29). Škola narodnog zdravlja imala je širok krug djelovanja među kojima se posebno ističu vlastita proizvodnja filmova za zdravstveno-prosvjetni rad i tečajevi koji su se provodili u sklopu Seljačkog sveučilišta. Osim sestara, učitelja i svećenika, veliku ulogu u prosvjećivanju imali su sanitarni i građevinski inženjeri, dok su u izgradnji i sakupljanju zdravstveno-propagandnog materijala sudjelovali i pripadnici različitih drugih profesija: fotografi i filmski režiseri, snimatelji i montažeri, slikari i ilustratori, pisci tekstova i sl. (usp. Dugac 2010:38-41).

22 Higijenski zavod bio je regionalna operativna higijenska ustanova (usp. Zebec et al. 1997:20).

23 Odjeljenje za socijalnu medicinu čine preostala dva Odsjeka: Odsjek za poučavanje naroda i Odsjek za proučavanje narodne patologije (usp. Zebec et al. 1997:29). 


\section{OD GAVAZZIJA I ŠTAMPARA PREMA ETNOGRAFSKOM FILMU?}

U razdoblju od 1940-ih godina 20. stoljeća nije bilo moguće provesti veća i ozbiljnija istraživanja, posebno u onim zemljama koje su bile direktno izložene ratnim razaranjima. Osim toga, ulaganje u znanost svedeno je na minimum s obzirom na to da su sredstva bila preusmjerena u vojne svrhe, a film je, kao relativno skupa metoda rada, među prvima ostao bez državne financijske potpore. Osim nedostatka materijalnih sredstava, politička je situacija također bila izrazito nepovoljna. Međutim, ŠNZ je ipak bio aktivan tijekom ratnog razdoblja s obzirom na to da im je snimanje bilo temeljna djelatnost za koju su imali predviđena financijska sredstva. Snimali su se namjenski dokumentarni filmovi čija je funkcija bila prije svega deskriptivno-informativna, a građi se pristupalo putopisno ili medicinsko-prosvjetiteljski (usp. Gotthardi-Pavlovsky 2009:43-44).

Nakon ratnih godina, početkom 1950-ih Gavazzi nastavlja sa snimanjem kraćih filmskih zapisa za Etnološki seminar kada ih je snimljeno samo četiri, od kojih je sam Gavazzi snimio jednog (O tatauiranju kod Banje Luke, 1952.) (usp. Gotthardi-Pavlovsky 2009:51-52). Već 1957. godine Gavazzi je potaknuo osnivanje odbora CIFE-a ${ }^{24}$ (Comité international $d u$ film ethnographique / The International Committee on Ethnographic Films) za Jugoslaviju, koji je postao 9. nacionalni odbor CIFE-a (usp. Majcen 1998b:166). Kao predsjednik jugoslavenskog odbora CIFE-a, Gavazzi je često primao pozive za sudjelovanje na raznim konferencijama vizualne antropologije. Ali, zbog svoje angažiranosti u brojnim drugim znanstvenim i stručnim područjima nije posvetio dovoljno vremena ni pozornosti vizualnoj antropologiji i etnografskom filmu u teorijskom pogledu, što se posebice očituje u izostanku tekstualnog adresiranja i problematiziranja spomenute poddiscipline. Iako, prema analiziranoj građi, razvidna je njegova upoznatost s radovima brojnih i u njegovo vrijeme aktualnih $i$ priznatih teoretičara vizualne antropologije i etnografskog filma (usp. Gotthardi-Pavlovsky 2009:61).

${ }^{24}$ The International Committee on Ethnographic Films (CIFE), utemeljio ga je Jean Rouch 1952. godine. 
Razmišljanju o metodama etnografskoga filmskog bilježenja i dalje nije bilo traga na našem tlu, kao ni institucionaliziranju i etabliranju etnografskog filma i vizualne antropologije kao poddiscipline u obliku u kojem se to dogodilo u SAD-u. Osim toga, nije se razvila adekvatna znanstvena produkcija koja bi se bavila etnografskim filmskim bilježenjem. Iz 1960-ih godina postoje dva kraća teksta Milovana Gavazzija Etnografski film, njegovo značenje i primjene (1964) u kojem etnografski film doživljava kao "naučni dokument", čija je vrijednost u vjernom bilježenju pojava, koje će na taj način ostati zabilježene i kada ih više ne bude u stvarnom životu (usp. Gavazzi 1964:58, prema Ghottardi-Pavlovsky 2009:61), praveći razliku između "etnografskog, tj. faktografskog filma" i "etnološkog”, tj. znanstvenog filma (Gavazzi 1964:62). Navedenu ideju razrađuje u drugom tekstu, objavljenom dvadesetak godina kasnije u Glasniku Slovenskoga etnološkog društva - O nujnosti kategorizacije etnografsko-folklornih filmov, u kojem generalno razlikuje "dokumentarni film" koji samo predstavlja određeni događaj, bez znanstvene namjene, i “dokumentacijski film" pod kojim podrazumijeva "čiste znanstvene filme, posnete po posebnom predhodnem proučevanju in natančni pripravi etnografsko-folklorne vsebine, ki bo snemana" (u čemu se vidi bliskost s kriterijima Margaret Mead) i koji je potkategorija istraživačkog filma. Taj, "dokumentacijski film" u našem bi slučaju bio "etnografsko-folklorni dokumentacijski film" (Gavazzi 1987:111-112) kojeg uže dijeli na: "1. kinematografsko-etnografsko-folklorne beležke", fragmente koji ne predstavljaju dovršene ili u cijelosti kompletne verzije sadržaja; "2. splošni monografski etnografsko-folklorni filmi", koje opet dijeli na "monografski lokalni filmi" i "monografski tematski filmi"; "3. primerjalni reziskovalni etnološki film" koji se sastoje od izbora neovisnih sekvenci iz različitih filmova kako monografskih tako i filmskih bilješki i koji predstavljaju i uspoređuju isti etnografsko-folklorni sadržaj različitih krajeva ili naroda (ibid. 112-113).

Gavazzi je osvijestio razliku između filmskog bilježenja i izražavanja. No njegov pojam znanstvenog izražavanja očito počiva na starijoj koncepciji koja kazivača i njegovu kulturu vidi kao objekt rada i koja nema osviješten problem istraživačeva tumačenja tuđe kulture ekvivalentima iz vlastite, pa mu je u tom smislu riječi i film objektivno sredstvo bilježenja u kojem istraživač nema potrebe pokazivati i obrazlagati svoju poziciju. 
Pritom Gavazzi ne razmišlja o distorzijama koje kamera i istraživač unose u snimanu materiju, odnosno ne uzima u obzir jednu takvu činjenicu koja je neizbježna kao dio konkretne metode snimanja. Iako je Gavazzi gledao Flahertyjeve i Rouchove filmove, za koje je tvrdio da su mu bili poticaj u njegovim vlastitim filmskim nastojanjima (usp. Križnar 1992:189, prema Ghottardi-Pavlovsky 2009:62), ništa od onog što je za njih bilo specifično nije primijenio. Gavazzi između ostaloga navodi kako je samouk u filmskom snimanju jer se u vrijeme njegovih početaka s tim nitko nije bavio, "jedino profesionalni filmski ljudi ali s tima nismo imali nikakve veze". Također je izjavio kako su ih ljudi na terenu prijazno primali, bez obzira na kameru u ruci, spominjući kako su "dijelom imali snimanje pripremljeno, to znači neki naši znanci na selu su priredili ljude za snimanje” (HR-HDA-1029 [3]). Ovo je vrlo značajna izjava kojom sam Gavazzi potvrđuje dogovaranje, odnosno unaprijed pripremljen, time i konstruiran, tijek događaja koji bi se trebao odvijati ispred kamera, što jasno pokazuje kako nije riječ o zaticajnim dokumentarnim filmovima.

U intervjuu s Naškom Križnarom iz 1991. godine osvrnuo se na film Jedan dan u turopoljskoj zadruzi (Chloupek, Gerasimov, 1933.), rekonstrukciju koja je proizašla iz fotofilmskog odjela ŠNZ-a. Navodno je i sam Gavazzi prisustvovao snimanju, iako bez ikakve funkcije. Izjavio je kako se radi o jednome iznimnom filmu koji mu je bio uzor premda je znao da je riječ o rekonstrukciji koja se znanstveno manje cijenila, barem prema strogim propisima koje je zadao IWF: "Svega toga više nije bilo onda. Ali je i kostim i geste i govor (to je u stvari bio netonski film), sve je to bilo krasno rekonstruirano tako da može služiti zbilja kao dokument." $\mathrm{Na}$ Križnarovo pitanje kako gleda na rekonstrukciju, Gavazzi odgovara: "Ako je rekonstrukcija apsolutno vjerna, a to mogu utvrditi etnolozi, sociolozi i drugi eventualni pomoćnici, onda se može učiniti. Ali, to treba u filmu i označiti - to je rekonstrukcija toga i toga", odnosno, bitno je istaknuti da je riječ o namještenoj situaciji. Prema ovakvom odgovoru, možemo zaključiti kako Gavazzijeva razmišljanja nisu nimalo zaostajala za razmišljanjima inozemnih kolega (HR-HDA-1029 [3]).

Filmovi ŠNZ-a napravljeni su kao pomoćni materijal radi lakšeg prodiranja ideja socijalne medicine do stanovništva ruralnih i osiromašenih područja. U tom kontekstu, film je bio prepoznat kao kulturološki posrednik 
i način komunikacije između liječnika i seoskog stanovništva. Međutim, osim instruktivno-zdravstvenih uputa, sadržavali su i socijalne elemente brige za poboljšanje materijalnog stanja seoskog gospodarstva, upoznajući tako gledatelje s načinom života, etnografskim osobitostima i kulturnim spomenicima. Danas se ti isti filmovi promatraju kao slike prošlih vremena, pobuđujući neka nova značenja od onih otprije osamdesetak godina. Poliperspektivnost na koju se upućuje, otvara prostor spoznavanju različitih pogleda na film, a ne zauzimanju, a priori, unaprijed zadanih i jasnih pozicija. Stoga, filmove Škole ne možemo uzeti kao jedine i "najtočnije" izvore etnografskih podataka. U suvremenom kontekstu oni predstavljaju samo jednu od više mogućih slika određenog vremena, približavajući tadašnju političku, društvenu i gospodarsku situaciju, kao i odnose (moći) prisutne na relaciji selo - grad. "Etnografski film" stoga je shvaćen kao posljedica povijesnih, političkih, kulturnih okolnosti unutar kojih i filmovi ŠNZ-a mijenjaju žanrovsku odrednicu (od zdravstveno-obrazovne prema etnografskoj) i dobivaju neka nova tumačenja ovisno o kontekstu unutar kojega ih se nanovo promatra i analizira. U tom smislu filmove ŠNZ-a možemo promatrati kao sliku u kojoj se zrcali vrijeme kojega više nema, ali koje je blisko vremenu u kojem filmovi nastaju i onome u kojem naknadno oživljavaju (usp. Urem 2015:55, 137, 179-80).

\section{PREMA ZAKLJUČKU}

Je li postojala profesionalna suradnja između Milovana Gavazzija i Andrije Štampara? Kakav je bio Gavazzijev stav prema filmovima Škole narodnog zdravlja i prema njihovim autorima? Gavazzi je bio suvremenik Štampara i ostalih suradnika Škole koji je imao vlastiti stav o tome kako bi etnografski filmovi, odnosno zapisi trebali izgledati. U skladu s tim te činjenicom da je filmove promatrao kroz pozitivistički vizir, filmovi Škole očito ga nisu previše interesirali niti je o njima promišljao kao o filmovima koji su u znanstvenom smislu relevantni kao izvori etnografskih podataka. Također, moguće je da medicinsko-edukativna podloga filmova nije kod Gavazzija probudila interes. Iako, Gavazzi i one filmove Škole koji nisu medicinske tematike ne svrstava među etnografske jer je riječ o namještenim filmskim prizorima, nedovoljno znanstvenim i objektivnim. 
Međutim, u kontekstu filma Jedan dan u turopoljskoj zadruzi, kako je ranije i navedeno, Križnar (usp. 1992:191) ističe kako je Gavazzi bio vrlo zadovoljan ovim filmom, smatrajući ga iznimno uspjelom rekonstrukcijom. Oduševljenost filmom bila je tolika da je Gavazzi dvadeset i sedam godina kasnije, 1960., film poslao na 2. Festival dei Popoli, festival etnografskog filma u Firenci gdje je osvojio Grand Prix (usp. Škrabalo 1984:74-75). Prema analiziranoj građi, suradnja između Gavazzija i djelatnika Škole narodnoga zdravlja je izostala. ${ }^{25} \mathrm{Je}$ li razlog tome bio drugačiji pristup pri proizvodnji filmova? Djelatnici Škole filmove su snimali, za razliku od Gavazzija, često s brojnom filmskom ekipom na terenu. Možemo postaviti i pitanje odakle Gavazziju svjesnost da snimanje mora raditi sam? Ruby o tome piše četrdesetak godina nakon Gavazzijevih početaka s filmskim medijem kada govori o kriterijima koje mora ispunjavati etnografski film. Naime, Ruby (2000:267) u svojim kriterijima navodi i onaj prema kojem film možemo nazvati etnografskim ako ga je proizveo antropolog, odnosno osoba s formalnom antropološkom naobrazbom. Gavazzi je u svom odnosu prema filmu ispunjavao postavljene kriterije znanstvenosti slijedeći svjetske trendove uporabe filma u znanosti - s jedne strane filma koji bilježi i prikuplja u službi spasilačke etnografije te s druge strane filma koji će provoditi diseminaciju znanja spašenoga u nastavi.

Kao što je već navedeno, ali i očigledno, etnografske filmove nisu stvarali samo antropolozi, etnolozi i etno-sineasti ${ }^{26}$ nego i redatelji i dokumentaristi. Iako, upitno je bi li zagovornici Heiderove i Rubyjeve vizualne antropologije filmove neantropologa uopće klasificirali kao etnografske (usp. Borjan 2013:21-22). Na ovom se mjestu jasno uočava problem određivanja i klasifikacije etnografskog filma, odnosno efemernost i promjenjivost te ambivalentnost definicije s obzirom na dominantnu

25 U članku Korespondencija Milovana Gavazzija u Hrvatskom državnom arhivu (Stipančević 2005) stoji kako je Drago Chloupek (1899.-1963.), liječnik i filmski redatelj, djelatnik Škole narodnog zdravlja i voditelj njezina Odsjeka za nastavu i propagandu, razmijenio dva pisma s Milovanom Gavazzijem. Sadržaj korespondencije odnosi se na rukovanje stipendijom koja je dobivena kao prva nagrada za film Jedan dan u turopoljskoj zadruzi na filmskom festivalu Festival dei Popoli u Firenci 1959. godine (usp. HRHDA-1029 [2]).

26 Termin koji koristi Etami Borjan (2013). 
teorijsku paradigmu. Gavazzijeve koncepcije filma kao etnološkog te njegova dokumentarna vrijednost $u$ svrhe znanstvenog istraživanja i prezentacije te Štamparove uporabe filma kao sredstva zdravstvenog prosvjećivanja uvelike odudaraju i značajno su različite. Točka u kojoj dolazi do spajanja navedenih koncepcija, iako idejno različitih, primjetna je tek naknadno, u vremenu kojem se sintagma etnografski film ustoličuje kao samorazumljiv koncept. Povijesni, politički, društveni i institucionalni okviri nastanka filmova Gavazzija i Štampara pokazuju kako sintagmu etnografski film ne treba olako i nekritički primjenjivati. Dapače, potrebno ju je kontekstualno razumjeti i shvatiti kao prostor propitivanja filmskog, dokumentarnog i etnografičnog. 


\title{
SPECIFIC FEATURES OF DISCIPLINARY AND INSTITUTIONAL APPROACHES TO ETHNOGRAPHIC FILM - MILOVAN GAVAZZI AND ANDRIJA ŠTAMPAR
}

\author{
(Translation)
}

SANDRA UREM

University of Zadar

Department of Ethnology and Anthropology

23000 Zadar, F. Tuđmana $24 \mathrm{i}$

Croatia
DOI: $10.17234 /$ SEC.27.6

Original scientific paper

Received: 1 March 2015

Accepted: 1 July 2015

This paper analyses the concept of ethnographic film from the position of two institutions from the beginning of the $20^{\text {th }}$ century: Ethnological Seminar at the Faculty of Humanities and Social Sciences of the University of Zagreb and the School of Public Health. This analysis explains the importance of ethnographic qualities of films made by these two different institutions that (in) directly represent the culture of the village. Diverse film production, very often uncritically brought under the common denominator of ethnographic film, will be reassessed by analysing the content of the film and discussing additional rewritings of their meaning and reception in the social and political context of the time.

Keywords: Milovan Gavazzi, Andrija Štampar, School of Public Health, ethnographic film, social medicine, health education

\section{INTRODUCTION}

The development of ethnographic film and visual anthropology has greatly depended on rapid technological progress and achievements that directly influenced the changes of the paradigms of visual and anthropological theories in light of the new possibilities of using film equipment on the field. The initial role of ethnographic film as the technique of recording and freezing the reality was related to the process of documenting the other, unusual and disappearing (saving ethnography), which was most often presented as a complement or an additional illustration of written ethnographies, university education, museum exhibits or an objective and true testimony of fieldwork. In such first visual recordings the voice of an observed subject was completely ignored and the authors of films had absolute control over what (and how) they record and present the subject 
matter (cf. Urem 2015:25). With time, changes have occurred in using the camera on the field, the way of recording and the recorded material itself, which took on the form of an independent film work that conveys a specific idea, attitude or a commentary of the author. In accordance with the abovementioned, as well as with the changes of the tradition within the anthropology, the role of the studied subjects in front of the camera is changing.

"The complexity of the phrase 'ethnographic film' is thus the result of an interdisciplinary approach, a shift within the master discipline, changes in the way of recording and using the visual material and unbalanced definitions." (Urem 2015:26)

David MacDougall does not consider ethnographic film the same as film ethnography (1981:6), but believes that ethnographic film is the one made to describe culture (ibid.) and defines it as a cultural category, wider than the films made within or for the discipline of anthropology (cf. MacDougall 1998:97-98). Anthropologist of visual communication, Jay Ruby, has an opposite attitude and four criteria. He also claims that ethnographic film has to be based on anthropological foundations theory and method (Ruby 1975:105) and that it can be made only by an anthropologist/ethnologist (cf. Ruby 1975; Gotthardi-Pavlovsky 2009:34). Karl Heider (1976) approaches ethnographic film and its characteristics in a way quite similar to Ruby's, suggesting that the best ethnographic films reveal "whole bodies, whole nations, in whole activities" by providing a cultural and physical context. Heider tried to solve the problem of defining ethnographic film by "ethnographic qualities" (cf. Heider 2006:2), thus grading the success of film transfer by ethnographic understanding of the people and the presented activities (cf. 1976:97-117 as cited in Banks 2001:141). Definition(s) of ethnographic film, professional directors who are not anthropologists, the relation between visual anthropology and its head discipline, balancing ethnographic films between science and art these are all the questions that have been discussed since the beginning of the discipline. The debate regarding the definition of ethnographic films is one of the most intense discussions in visual anthropology, including the issues related with representation, authority, participation, construct, 
authenticity, value, etc., which have been raised by many anthropologists like James Clifford (cf. 1988 as cited in Picton 2011:422). Ethnographic film is most recognizable as a subcategory of the tradition of film documentaries with which it shares many similarities, while the attribute "ethnographic" has been assigned considering the production, intention or method and not only the content of the film (cf. Ruby 2000 as cited in Durington i Ruby 2011:192). Years of debating while searching for an appropriate definition of the ethnographic film have not resulted in an unambiguous definition that can be used by all authors or selectors of festivals. It is precisely this inability to offer a strict and precise definition, however, which allowed a quick and dynamic development of the subdiscipline, as well as its presence and popularity outside the strict academic and scientific circles (cf. Urem 2015:62). Visual anthropology aims to teach anthropologists to observe film as a cultural representation, instead of approaching it solely as a document - a scientifically reliable source of ethnographic data that excludes the role and the influence of the author (cf. Puljar D'Alessio 2002:40).

It is not possible to question the phrase ethnographic film on the example of the films made by the School of Public Health ${ }^{1}$ without having insight into the complexity of social, cultural, political, institutional and ideological framework that allowed for visual recording to be labelled as ethnographic. The paradox of this otherwise common research approach can be seen in the fact that films like the ones of SPH were not originally considered to be ethnographic films. Moreover, at almost the same time they were made there were also film recordings made during the field research of Milovan Gavazzi ${ }^{2}$ directed by the then founded Department of Ethnology ${ }^{3}$. To a careless observer film records that Gavazzi labels as ethnological film might seem quite similar to the films made by SPH; in

\footnotetext{
${ }^{1}$ Hereinafter: SPH or the School

${ }^{2}$ Milovan Gavazzi started filming by camera in 1930, fascinated by the new medium that could have recorded phenomena visually and in movement (cf. Križnar 1992:187).

3 In 1927 Milovan Gavazzi left his job at a museum and started working as a professor at the Faculty of Humanities and Social Sciences of the University in Zagreb at the Department of Ethnology, Seminar of Ethnology - today the Department of Ethnology and Cultural Anthropology (cf. Gotthardi-Pavlovsky 2009:27).
} 
the selection of scenes, message and the content. The activities of different institutions that made and used films which consequently gained various descriptions in the 1920s, including the mentioned label ethnographic film, will be presented in this article. The comparison and analysis of the production of visual presentations of the two institutions, the Seminar of Ethnology at the Faculty of Humanities and Social Sciences of the University in Zagreb and the School of Public Health, and the purpose of using the camera by their most prominent representatives who adhered to different principles of the discipline (Milovan Gavazzi and Andrija Stampar) aims to point to the relations between the two institutions which produced visual records almost at the same time and at the time when hardly anyone had a camera. I will also try to present the origin of the phrase ethnographic film in the films made by SPH, their historical and social anatomy and institutional specifics. These films, whose ethnologically relevant content evokes their subsequent genre determination and labelling with the phrase ethnographic film, are studied as documents of culture and time, which transcend their original purpose by becoming the reflection of more recent times.

\section{ETNOGRAPHIC FILM ACCORDING TO MILOVAN GAVAZZI}

Ethnologist Milovan Gavazzi had a leading role in the Croatian cinematography, more specifically in the beginnings of experimenting with ethnographic film. Since he did not have enough film equipment at his disposal, his attempts to record cultural specifics were determined by the selection of the events he planned to record before the act of recording itself. Film activity of Milovan Gavazzi started in the 1930s, when, as an ethnologist, he used an amateur silent camera to research the culture of his country in accordance with his scientific interests and attitudes (cf. Gotthardi-Pavlovsky 2009:34). He recorded everything which sparked his interest, or everything he regarded as a divergence from the typical urban daily life. He left the parts he considered to be normal, clear and ethnologically irrelevant as empty blanks. Gavazzi's "theoretical postulate - everything that is different within the rural culture is probably old as well - follows the construct of peasantry as a fixed category which preserves 
old tradition" (HR-HDA-1029 [4]). In the time when traditional culture of the village underwent significant changes, Gavazzi's camera recorded certain segments of traditional culture of Croatia that was disappearing or was about to disappear from the life and practice of everyday life. Focused solely on the physical manifestation of the topic he was recording, he studied segments of culture isolated from the synchronous social structure that he, in accordance with the cultural and historical paradigm, compared with similar examples from the South Slavic and Eurasian areas in order to reach the oldest layers of culture and determine their origin. Gavazzi makes films, or film records, in accordance with the beliefs of Seljačka sloga (cf. Pletenac 1996) and tries to save the vanishing culture using the camera before it disappears.

Traditional culture ${ }^{4}$ was a political leitmotif in the period when national countries of European nations were trying to be formed or were dreamed of since it is precisely traditional culture that differentiates us from the others and within which we can find essential national symbols. Traditional culture is, however, a construct because it always includes selected and idealised elements of culture that are changing and adjusting to new circumstances, which results in a new tradition being created and constructed, the one which is evoking its historical authenticity without

\footnotetext{
4 Although the problem of the phrase "traditional culture" within the anthropological discourse has been tackled with, relativized and deconstructed, it is addressed in this paper as the term of rural culture that signifies the transfer of elements from one culture to another as indicators of a form of representation. "Traditional culture" evokes the culture that is connected with pre-modern and preindustrial societies, which determines it as original and traditional. It uses its representative forms and elements as carriers of national identity. The activities of Seljačka sloga in rural areas in the period between the wars included cultural activities which were based on the existing traditional culture and had a strong political function. The essence of the political function was the result of understanding "cultural programme only within the conservative concept of rural culture and fairly explicit national exclusiveness" that can be seen in the research of the beginnings of folk culture, when "borrowings" were uncompromisingly rejected and the "originality of culture was insisted on, developed in faraway villages, inaccessible to 'foreign' civilization - keepers of the 'national' culture being" (cf. Rihtman-Auguštin 1979:11-12).
} 
having a visible distance from "the original tradition". Despite this fact, traditional culture is "always presented as absolute and authentic, a significant truth about the past" (Lass 1988:457, as cited in RihtmanAuguštin 1992:26), although we are dealing with the secondary and mediated existence of its elements which have gained a new role (cf. Rihtman-Auguštin 1978:21). It was more than a reason enough to protect it before it completely disappears or is transformed into new forms (cf. Gotthardi-Pavlovsky 2009:31-32). The selection of scenes shows the constructiveness of Gavazzi's film records, regardless of the fact that in the large part of his oeuvre he strictly complied with the regulations of the Institute for scientific film (Institut für wissenschaftlichen Film, IWF, Göttingen) and insisted on the scientific quality of the film document ${ }^{5}$. Films which were agreed to be made with the staff of the abovementioned Institute had to be "transparently scientific", "an absolute document, not propaganda or something similar" (Križnar 1992:190).

Gavazzi's enthusiasm with the new media that can visually record phenomena $^{6}$ and thus complete what was written or photographed, as well as with its accessibility, can especially be emphasized in his method of work and in the context of the new film media. Motifs of Gavazzi's work with the camera or the act of saving the culture which is disappearing by recording it inevitably shaped the documentary style of his recording. Vjekoslav Majcen also says that Gavazzi evidently makes film recordings,

${ }^{5}$ German anthropologists emphasized the scientific dimension of making films and set the standards of scientific purity in a film. In 1959 they issued the Rules for Film Documentation in Ethnology and Folklore. They put the emphasis on the anthropological component in the film, recording authentic events without the use of dramatic angles of recording and camera movements and avoided editing or used it to achieve representativeness of the material (cf. El Guindi 1998:465).

6 Gavazzi had a small amateur silent camera, Agfa movex camera, so he could not have recorded sound, i.e. if he recorded sound by some other means, he was not able to synchronise it with the belonging image. It resulted in mute film recordings. Only 12 meters of film tape fit into the cassette so he often had to stop the recording and change the tape; thus, he could not have recorded events and activities in real continuity. (cf. Križnar 1992:187). 
by comparing his works with those of Flaherty ${ }^{7}$ from the 1930 s, as well as those of Jean Rouch ${ }^{8}$ from the 1950s, who were Gavazzi's role models:

"Gavazzi did not want to realise similar complex film projects. His interest in film was strictly limited to the exact (or scientific for the period in question since it had to be scientific to be exact, author's comment) visual recording of a specific phenomenon." (Majcen 1998b:166)

Gavazzi himself stated the original intention of documenting: "So the idea occurred to us to document at least that which is in movement" (Križnar 1992:187). Later, in the 1960s, Gavazzi suggested the division of ethnographic film works into types, among which he mentioned

${ }^{7}$ Robert Joseph Flaherty was born in 1884 in Iron Mountain (Michigan, USA). In 1910 he went to the Hudson Bay region to conduct research for a mining company. Then followed three expeditions during which Flaherty started recording the Inuit community that lived in the area. He lost the recorded material by accident and left for the fourth expedition in 1921 to record the film material again. Although Flaherty was first a researcher and a mineralogist, his film Nanook of the North was released in 1922 and achieved international success in movie theatres. With the abovementioned film he affirmed his position in the film industry and his name soon after began to be mentioned among the pioneers of documentary film (cf. Engelbrecht 2007:467-468). Flaherty can also be called the first cinema worker who used the participant-observation mode of documentary film (cf. Nichols 2001:168-177), which can be seen in the Nanook of the North that "shows daily activities of the Canadian Inuit community by creating an exotic, yet an acceptable image of the Other" (Borjan 2013a:83).

${ }^{8}$ Jean Rouch was born in Paris in 1917. He worked as a civil engineer in Nigeria where he first went in 1941. With time, he developed interest for the rituals of the local population (trance, obsession rituals, traditional ceremonies and daily life) and he conducted field research that resulted in ethnographic essays and films. Before he made his first films, Rouch graduated from the Faculty of Anthropology in France. He is important for the history of ethnographic film because of his experimenting with the film language and playing with the conventions of fictional and non-fictional film (ethno-fiction), but also as an author who started with the collaborative approach, reflexive film and the truth cinema (cinema vérité - combined ideas of Soviet director Dziga Vertov and Robert Flaherty). Due to his avant-garde innovations in his films and replacement of an "objective distanced view by a multifunctional construction of reality", Rouch's films were not widely accepted by anthropologists (cf. Borjan 2013a:101-123; Durington and Ruby 2011:198; Engelbrecht 2007:477-478). 
cinematographic-ethnographic-folklore beležkas he was making himself (Gavazzi 1987:112). In the context of his scientific work he only gave an ancillary role to the film as

"a tool which was first intended for the students of ethnology and experts who study traditions [...] so that they can actually see phenomena in movement [...] which would not be possible if other instruments were used." (Križnar 1992:189)

In his written records about the film, which are rather scarce, Gavazzi wrote that it was about

"a new form that resulted from the need to use a short form to define a film genre which 'emerged' from a long period of searching for its own designation and place, especially within documentary or educational film." (Gavazzi 1964:57)

Gavazzi places the beginnings of ethnographic film far back into the past, in the time when educational films about foreign countries and their native populations were made (cf. ibid). Such films had the status of film records that, just like the text, were as significant as textual records.

Despite his modest written contribution and insisting on making scientific films, Gavazzi was aware of the problem of placing an ethnographic film within a scientific discourse or (un)acceptance of its scientific relevance and value. The consequence of such an approach to the film is demonstrated especially by the inequality between ethnographic film and written ethnography. Gavazzi is also aware of the problem of defining the ethnographic film as a document, relevant and applicable in scientific documents because:

"It is well known that ethnographic film - professionally made, accurate and technically flawless - is a 'scientific document'. Film records, made around fifty years ago, are dug up from the bottom of the archive because they often preserve the live image of something that cannot even be traced anymore. The best film material is taken from these films and with such old material new films are made, sometimes of first-rate importance, for scientific purposes." (Gavazzi 1964:58) 
Gavazzi also correlates a film document with the realistic specific flow and duration of an event of ethnographic significance

"because ethnographic film inevitably shortens the real event, which imposes the selection of ethnologically most significant segments from the longer entity of the recorded activities (which provokes the question of the most 'significant'!...), it is 'snatched' - as a photography - from a much wider cultural context that includes it, etc." (ibid. 59)

In the abovementioned sentences Gavazzi explained the way old ethnographic recordings were used, for which he continued to claim that they presented and preserved "the live image of something that cannot even be traced anymore", pointing to the primary function of the ethnographic film as a visual testimony that preserves or generates permanent images (cf. ibid. 58). This approach is criticized today since it is apparent that such a recording is not free of the affinities of its author (their interests and intentions) and the circumstances under which it was created. The recording preserves one image, one author and one moment so today, when we see it, we see and observe something different from the audience that observed it at the time when it was made. Gavazzi classifies film (and isolates it) as "a strictly scientific document" and as an "ordinary "document of culture", and especially emphasizes the characteristics that reflect "the facts and authenticity in the best possible sense" (cf. ibid. 59-60). He also knew the methodology of Flaherty's work to which he refers to in the context of the growing popularity of his films as first-rate documents; he claimed that the production of such documents could have been done only with the necessary spontaneity during the recording and the minimum of directing (cf. ibid. 60). Gavazzi also commented on the value of film in education, especially as a tool in ethnological and cultural and anthropological classes claiming that the film was:

"the most perfect tool that supplemented activities and facts from the reality, a powerful tool for everyone due to its natural attractiveness, which can be used reasonably and moderately in general education. Moreover, its role as a social and pedagogical tool is especially emphasized, and is always, to a larger or lesser extent, directed to increase the inclination towards and 
understanding of the foreign nations, their culture and way of life and their faraway troubles and joys that are very distant to sympathise with." (ibid. 61-62)

Gavazzi differentiates between ethnographic and ethnological film. He defines ethnographic film, which is only factual, as a film with descriptive characteristics that accurately collects and documents facts as they are (cf. ibid. 62-63). It is a film made by a research ethnographer, well educated - in ethnology and ethnography, as well as in photography and film (cf. ibid. 62). Ethnological film, on the other hand, Gavazzi defines as a scientific and planned film that provides the observer with specific, already acquired ethnological knowledge or a problem in the form of a film to be further examined (cf. ibid. 62-63). Still, the emphasis is put on the ethnographic film which is presented as the result or the product of a research ethnographer. These products are the results of inevitable research and saving ethnography, what Gavazzi's film records mostly are. When we have a visual material we call a film record, we never know the context of the recording. In the context of recording a document we thus always talk about the document of the given moment. Gavazzi shared opinions and undertook activities similar to that of world-famous authors and visual anthropologists, but the belief in the significance of comparison he attached to films, like his fellow anthropologist Margaret Mead, is mentioned most often (cf. ibid.). It is apparent that Gavazzi was aware of the film as a construct, but he reluctantly relinquished the terms like authenticity and originality. Gavazzi claimed that ethnographic film could be a kind of an irrefutable scientific arbitrator in case of an ethnological problem or ethnological interpretation (cf. ibid. 58). He believed that these films (or true and authentic film records) would serve to correct previously incomplete or wrong ideas, formed on the basis of superficial or quick observations of a process of production, customs or rituals. $\mathrm{He}$ especially emphasizes the use of film records in special occasions, like better perception and analysis of often fast movements in dancing, work movements, etc., which can be achieved by slowing down or pausing specific records in order to study them, etc. These claims clearly show the attitude adopted by Gavazzi - observation and analysis of films as irrefutable evidences, belief that what we can see and what we can see 
more than once, pause and analyse - a sufficient and clear warranty of truthfulness.

For Gavazzi ethnological film can be a document of something that took place (when he talks about reconstruction) or is still taking place (or has not been reconstructed so it can be used for ethnological research) but he emphasized a comparative ethnological film as a better ethnological instrument (comparison of clips from some films within a film) (cf. Križnar 1992:194). He also believed in the importance of the director being an educated ethnologist in order to reduce possible mistakes during the recording to a minimum since the "danger of making a mistake is far less possible if an ethnologist, especially an experienced ethnologist and an experienced film director, makes the recording himself" (ibid. 195). Gavazzi defines ethnographic film as a new reference ${ }^{9}$ that resulted from the need to define a new film genre which had been developed during a long period of time and required a special name and place, especially within the frame of a documentary, professional or a scientific film. He places the beginnings of ethnographic film far back in the past of film records, to the time when educational films about foreign countries and their native population were made. Next to such unsystematic and mostly fragmentary films with ethnographic content, there were also efforts to record numerous activities from the life and culture of so called primitive and half-civilized nations, along with the films as scientific documents. Gavazzi calls such a recording method as: "ethnographic, in the strict sense of the word, with planned units that have the significance of a scientific document" (Gavazzi 1964:57). Gavazzi emphasized the value of films as units, thus disagreeing with the strict rules of the Institute for Scientific Film in Göttingen and their archive Encyclopaedia Cinematographica ${ }^{10}$ that only took specific scenes and individual units, regardless of the long duration of specific customs as a whole - thus focusing on encyclopaedic units and not on films (cf.

\footnotetext{
9 New at the time when Gavazzi's text was written; in 1964.

10 The cooperation of IWF and Milovan Gavazzi manifested in the obtained material for recording that Gavazzi had often lacked. It can be assumed that Gavazzi followed the rules of IWF in many of his film records so that they would be included in their archive as scientifically significant.
} 
Križnar 1992:195). This information is very interesting because Gavazzi cooperated with the Institute and adjusted to their strict criteria which were guaranteeing that the film was scientific, or the sequence of the record he had aspired to. His actions gave the impression that he was completely supporting such method of filmmaking since he made a great deal of ethnographic records. According to his criteria, almost all films were to be seen as ethnographic documents, most of which could have been used and which were to be used for research and presentations to students, etc. (cf. ibid. 196).

We can say that Milovan Gavazzi, author of many ethnographic film records, was the first Croatian visual anthropologist who examined the concept of ethnographic film or visual anthropology only at the end of his career, discussing precisely ethnographic and film topics, his fascination with the film Nanook of the North (1922) and the admiration he expressed for Jean Rouch and his works (cf. Križnar 1992 as cited in Borjan 2013:13).

According to the reports from the field, which are kept in the Croatian State Archives in Zagreb ${ }^{11}$, Gavazzi made preparations before the actual process of recording in order to reduce unexpected difficulties to a minimum. He would call such recordings a film document, more valuable if there had been changes in the then current circumstances. The example of pottery in Veli Iž helped Gavazzi to illustrate that it was an "urgent task to save this symbol of our folk handicraft for eternity as a film document". This example clearly shows that the act of recording is never a completely pure document free of the influence of the author. It would probably be more appropriate to talk about the image, and not the document that does not necessarily save a specific custom, but puts its captured image in the given frame of the film tape or photograph, thus protecting it from the ravages of time - the recorded custom will not change, whereas the custom that lives surely and inevitably does change. The document itself is not a specific custom, but it represents a number of (visual) information about the custom the way the author (of the film) sees it. Films that are part of the

11 Report on the making of ethnographic films, no.10/1964, Zagreb, 1 October 1964 (HRHDA-1029 [1]). 
film library of the Department of Ethnology were made for scientific and educational purposes. This purpose was probably one of the reasons why Gavazzi followed the instructions of objective and scientific production of films as much as possible, with minimum intervention of the author. Such method of recording adhered to theoretical paradigms of the time, as well as the instructions of IWF that Gavazzi cooperated with.

When we discuss the context of the appearance and development of ethnographic film and visual anthropology, films or film records which gained the prefix ethnographic were not made any later if compared with other similar events in the world. As it was already mentioned, not long after Flaherty's Nanook of the North Croatia got its first ethnographic films (in the wider sense of the word), like film (film record) Seljačka svadba $u$ Hrvatskoj ${ }^{12}$ (February, 1922) from the series that has never been completed Narodni život i običaji ${ }^{13}$ (cf. Majcen 1995/1996:123; Gotthardi-Pavlovsky 2009:23-24). If we analyse the style of making Seljački svatovi iz Sunje ${ }^{14}$ (Seljačka svadba u Hrvatskoj is the other name of the same film record), we cannot speak about the film, but the film record that looks like a genuine document, on which Gavazzi insisted while making his (film) records. By focusing on the culture that is disappearing, he made film records documents from the tradition of the villages of Croatia and Bosnia; pottery technique from Potravlje (near Sinj) and from the island of Iž; fishing by using fishing net migavica from the island of Pašman, nitting jalba; and the funeral on sleighs in Trg near Ozalj (cf. Ghottardi-Pavlovsky 2009:32).

Film historian Vjekoslav Majcen writes that the recording style is determined by continuous recordings of long sequences, with the camera fixed in the frame (with the exception of short panoramas) or without the change in the distance of the camera, with pauses made only because the film cassette needs to be changed. The scenes repeated in reality are repeated in the film record as well, which makes the film closer to the real duration of the observed event. The film plan most often used in the recording style

\footnotetext{
12 Village wedding in Croatia, TN

13 Folk life and customs, TN

14 Village wedding in Sunja, TN
} 
is the medium shot, which includes the complete human figure with the immediate surroundings of the recorded action, as well as the close-up (cf. 1998b:165). While recording Gavazzi was very mobile with a small camera (Gavazzi in Križnar 1992:188), but he probably considered such frames more ethnographic, i.e. more appropriate for the purpose they served (cf. Gotthardi-Pavlovsky 2009:33). Gavazzi thus made recordings which are better not to be called films, especially if we believe in the definition given by Aleksej Gotthardi-Pavlovsky (ibid. 9-10), according to which a visual work can be called film if it expresses the author's attitude by using film instruments (cf. Gotthardi-Pavlovsky 2002/2003). ${ }^{15}$ Most often Gavazzi recorded by himself, without a (professional) film team so there is the question whether his independent work was a matter of choice, necessity or, most likely, both. We can assume that he insisted on the scientific quality of the film record and thus avoided to have many people on the location of the recording so that the originality of the e.g. custom he was recording would not have been compromised.

\section{FILM ACTIVITY OF THE SCHOOL OF PUBLIC HEALTH IN THE FIRST HALF OF THE $20^{\text {TH }}$ CENTURY}

In the almost exact time period, doctors and their colleagues from the Zagreb School of Public Health used their own approach to (ethnographic) film. Their ethno-film view of their own rural Other was even more superior than that of the ethnologists. It was the view of health professionals who were shocked with the existing hygienic, social and economic and medical conditions in which lived the poor rural population. Tanja Bukovčan helps us understand the importance of such a view in her comment stating that

\footnotetext{
15 Accoding to Etami Borjan (2013:22) the followers of conservative visual anthropology can question the classification of works made by non-anthropologists, which, according to the author, in the widest possible sense can be classified as a subcategory of ethnographic film. The growing use of digital media has changed the concept of the ethnographic film which is not only connected with academic circles nowadays. Thus, its ultimate goal, the intention, target audience, distribution and production have changed.
} 
"the colonial character of their view was scientific and professional, based in the politics and power of the medicine system" (cf. Borjan 2013:14).

In the first half of the $20^{\text {th }}$ century in Croatia, parallel with Gavazzi's first film records and the development of the film method of expression and the film industry, consciousness was raised about the effectiveness of using film for the purposes of education and enlightenment, primarily inspired by the motives of promoting health and education (cf. Gotthardi-Pavlovsky 2009:25). Unlike the ethnological films Gavazzi made for professional audience and from the position of an ethnologist who established his authority as a university professor, scientific and enlightenment character of the movies of SPH is built on the authority of Andrija Štampar and his idea of social medicine. Štampar's fascination with the film as a medium that can be used for the purposes of health enlightenment starts at about the same time when Gavazzi and Flaherty started with their work. Film activity of SPH was part of public social, educational and cultural activities of the institution, which were done in the specific conditions of the period between the two wars - the films can be observed within the context of all social activities and their manifestations in the Croatian culture of the period. The development of social medicine after the World War I, which was primarily directed to the people of rural and poor areas and encouraged by the League of Nation's Health Organization, favoured the development of educational films (cf. Majcen 1998:159-179). Department of film and photography of the SPH had a leading role in the production of educational films in the area of contemporary Croatia. We can draw a parallel with the observations of Anna Grimshaw (2001), who claims that it is not possible to understand the characteristics that define the principles of scientific ethnography and documentary cinematography outside the authentic historical context. She writes about the encouraging enlightenment vision of the world which promotes the goal, integration, rationalism and knowledge on the example of the works of A. R. Radcliffe-Brown and John Grierson from the period between the two wars (cf. 2001:58). These are the characteristics which determine the time of exceptional changes and innovations, noticeable in the times when cinematography and modern anthropology were emerging. Film projections were used to effectively promote and encourage hygiene and health education with the purpose of preventing and eradicating specific diseases (tuberculosis, malaria, dysentery) and disorders that had 
a negative impact on health (alcoholism, irresponsible sexual behaviour, etc.) (cf. Gotthardi-Pavlovsky 2009:26). The School of Public Health organised lectures which were most often accompanied by the screenings of educational films. In the period between the two wars epidemic diseases spread extremely fast so urgent and efficient measures were necessary, most effective of which was the new medium. The film (image in movement) left the audience, which was not informed about the scientific achievements of the time, with an overwhelming impression. Education via the medium of film was the world trend, and Andrija Štampar himself encouraged this method of education, which he mentioned in his writings (cf. Majcen 1998a:151).

The basic purpose of the valuable production of educational, documentary and animated films of the School of Public Health (19271960) ${ }^{16}$ was to enlighten the population about health issues. At the same time, the production also contributed to the creation of the school of Croatian documentary and animated film. The tradition of making educational films was continued after the year 1945 and the production continued until 1985. At the very beginning of the activities of the School there were adaptations of health documentary foreign films and independent works of the School's employees (cf. Zebec et al. 1997:32). The first phase of the activities of photographic and film laboratory of the School was assessed as the phase of experimenting - a right film expression was trying to be found - the one that would serve the purpose of hygiene propaganda and captivate the audience. Considering the lack of records about the reactions of the audience to the presented films, Željko Dugac's account, given in his book, is extremely valuable. His account says that the screening of the films in the village was accompanied by many problems. People would constantly interrupt the screenings with their remarks and comments and let trivialities divert their attention, like mocking the way an actor held a hoe or dug, and so miss the main message. Such a film was not authentic for them because it falsely presented their daily life (cf. Branko Cvjetanović - report by

\footnotetext{
${ }^{16}$ In the period from 1927 to 1960 the total of 165 films were made and from 1927 to 1939 the School made 66 films, most often classified as educational and cultural films about medical, hygiene and other problems or health and educational films (cf. Dugac 2005:155).
} 
phone in Dugac 2010:128). Urban manners of theatre actors (present in the first stage) often provoked laughter so in the following fifteen-year long phase of documentary film a new trend was set with peasants as actors and the completely new film crew, which resulted in the greatest number of scientific and educational films used for the fight against social diseases (cf. ibid. 34). The screenings followed by short lectures were well attended by the local people (cf. Cvetnić 2009:73). This growing interest was probably the result of the fact that the film was a new medium-images in movement that the viewers observed with interest and excitement. The projector used for film screening was operated by a film operator manually and the films were projected on the stretched canvas on the wall of the hall in Mraclin. In his book Mraclin: kakje negda bilo. Mjestopisne i povijesne crtice $^{17}$ (2009) Cvetnić mentioned some anecdotes from the screening as well, saying how the comments of specific scenes were interesting and funny, especially made by the viewers who were late and loudly read the titles or the accompanying text (cf. ibid. 74). In the second period (from 1930 to 1939), the School was separated from the Hygiene Institute in Zagreb and remained "subordinate to the Ministry of Social Policy and National Health" (cf. Zebec et al. 1997:42). During this period the work in the school took place in rather different circumstances and crisis of economy, and in the difficult political atmosphere as the consequence of the assassination of Stjepan Radic and members of the Croatian Peasant Party $^{18}$ in the Belgrade Parliament in 1929, transformation of the HSS into a movement, the constant tension with Belgrade and, finally, the assassination of King Alexander in 1934 (cf. ibid. 43).

\footnotetext{
17 Mraclin: the way it used to be. History and life of the place, TN

18 Hereinafter: HSS, TN
} 


\section{SOCIAL AND HEALTH EDUCATION OF THE SCHOOL OF PUBLIC HEALTH AND POPULARISATION OF SCIENCE IN THE CONTEXT OFTHE PERIOD BETWEENTHE TWOWARS}

It is partly possible to evoke the beginnings of the time when film production started if the wider context is understood. The time period I refer to in this article overlaps with modernism ${ }^{19}$ in a wider sense and relates to the last big period in the social, political and cultural history of the West, which began at the end of the $18^{\text {th }}$ century and lasted until the onset of postmodernism in the other half of the $20^{\text {th }}$ century ${ }^{20}$. It is the period characterised by the dismissal or innovation of tradition in accordance with the specific circumstances of the development of modern industrial societies. One of the definitions that reflects the efforts of modernism relates to the social and progressive trend of thinking that reinforces and reassures the power of creation, improvement, shaping of the human environment by the human beings themselves, with the help of practical experiments, scientific knowledge or technology. Therefore, regardless of the misfortunes of the abovementioned period of the world history, daily life continued with its course, adjusting to the new circumstances and shaping them. As in all other European countries, the art deco style was widespread and included a large period of time called jazz age, roaring twenties and swinging twenties in accordance with the activities that were widespread around the world and were popular in Zagreb as well: jazz bands producing the new sound, new dances,

19 In the context of this paper the term modernism is used as a reference to the time, period or its specific qualities (cf. Milenković 2007:5). The definition of modernism as the result of social differentiation and specialisation in modernity is widely accepted and is most often related to capitalist modernization in the West, after the $19^{\text {th }}$ century (cf. Habermas 1981:7 as cited in Milenković 2007:16). In sociologic imagination modernity is characterised by the breaks of feudal and religion orders in European societies, the process of rationalisation, social and economic differentiation, urbanisation and industrialisation. In this context the dominant theoretical project is the one recognised as enlightenment and represented as "universal rationality in the form of positivist social learning" where social life and the life of an individual is shaped by objective laws believed to exist in the world of the nature (cf. Coombe 1991:189 as cited in Milenković 2007:16).

${ }^{20} \mathrm{http}: / /$ www.enciklopedija.hr/Natuknica.aspx?ID=41465, accessed March 12, 2014 
Charleston, fascination with dance music played on the gramophone, beauty pageants during the summer, the world of the night clubs, cabarets, fashion shows and stars, as well as new technological achievements, the plane and zeppelins, large ships and travels across the ocean ${ }^{21}$. The differences in the daily life on the relation village - town were huge, although it was going on only about 10 kilometres apart. While the citizens of Zagreb enjoyed the benefits of the progress of civilization, only a couple of kilometres away, the people who lived in the rural areas lived in extremely bad and unhygienic conditions, in poverty, following the traditions and habits from some other and past times, if observed from the perspective of the town. Building up the traffic and communication network by constructing roads and, especially, railways, enabled a better connection of the village and the town. Good connections between the village and the town decreased the isolation, which surely resulted in a greater openness to the new ideas that were coming from the town, as well as the reorganization of the rhythm of life.

At the same time, the 1920s and 1930s were hit by the big crisis which occurred as the result of the atrocities of the war, economic difficulties and poverty, ideological and political turmoil, insecurities and new militarisation. The chaos and insecurity of the period between the wars has greatly affected the appearance of many innovations and the development of new technologies and changes in the social order. After the abolition of the Habsburg Monarchy, Croatia entered the Kingdom of Serbs, Croats and Slovenes, later known as the Kingdom of Yugoslavia. The dramatic events of the time left trace on the lives of the people and the development and organization of the new form of health protection (cf. Zebec et al. 1997:5). This was the period we identify as the beginning of health education, when the School of Public Health in Zagreb under the management of Andrija Stampar played a crucial role (together with other similar institutions in the wider area of the Kingdom of SHS) (cf. Dugac 2010:2). Stampar's ideological principles were based on the ideas of social medicine presented in the ten items of a kind of a manifesto, so called our ideology, which were

${ }^{21} \mathrm{http}: / /$ fuliranje.com/zanimljivo/, accessed March 12, 2014 
published in his book Pet godina socijalno-medicinskog rada u Kraljevini $S H S^{22}$ (cf. Dugac 2005a:24-25).

In the complex process of modernization which was accelerated by the world war, the then existing order of values was lost, traditional culture went through strong transformation and the crisis of the identity was deepened. The crisis was worst in the village which included the biggest part of the Croatian population and where modernization with a number of accompanying innovations was often met with great suspicion and rejection. In the economic plan the process of modernization was considered to be responsible for the impoverishment of the village (cf. Sremec i Nikolic 1941:103-104). The movement of Radic brothers tried to rebuild the shattered identity and overcome the crisis. Their pragmatic approach, based on the reconciliation of the social opposites of classes, aimed to return the shaken self-esteem to the rural population and make them an active social, political and an economic subject ${ }^{23}$ (cf. Leček 1995:117-118). At the end of the 1930s Štampar himself developed cooperation with the organizations that were formed by the HSS ${ }^{24}$ (cf. Dugac 2010:131-133), which proves the existing relation between HSS and SPH that systematically provided the rural area with education and thus complemented their activities. The ideas of SPH were realised faster and more comprehensively by the use of the film medium (cf. Urem 2015:95). The economic burden on the family, natural growth of the population and reduced mortality of infants achieved by better medical infrastructure resulted in rural overpopulation that in the 1930s burdened the life of the people in the whole country (cf. Bićanić

\footnotetext{
${ }^{22}$ Five years of social and health work in the Kingdom of SHS, TN

23 One of the methods employed by the then influential Croatian Peasant Party with the aim of including the village into the modern society as easily as possible was connected with the intense "cultural and educational activities of Seljačka sloga, organization of classes for the illiterate, lectures, starting church choirs, libraries, reading rooms and rural communities. In urban areas this appeal to the roots was especially reflected in the beginning of 1930s, when there was a literary movement focused on the Croatian village $[. .$.$] and the expansion of social urban and rural topic in literary and art works. The$ original rural art expression was encouraged and studied, from folk art to the evaluation of traditional form of tools, customs and way of life" (Majcen 1996:130).
}

24 Seljačka sloga and Gospodarska sloga. 
1940:147-148). Those who returned to the area after they had spent a long time working in another cultural and economic milieu had a great influence as well since they brought new, modern way of thinking and worldview, mostly radically different from the local rural tradition. Therefore, it can be concluded that the mobility of the village population, social differentiation and hierarchy within the village, increase of commercialization and an increasing market-oriented economy of agricultural estates lead to the social process of change into a modern order. (cf. Grandits 2012:161-164). Village teachers had a great role; their activities implemented the national system of education in the village, completed the local and family acculturation and changed the rural and family standards of value. The activities of the School, whose significant part were their film products or programmes and projects that the employees of the School were undertaking within the programme of health education (with the goal of improving hygiene and health condition of wide layers of the society), can also be related to a wider and more complex process of modernization. The basic activity of the School was the study and education of the people, which greatly influenced the acceptance of the modern understanding of health and disease, defined by the dominant medical system of biomedicine and adequate concepts of the Western worldview that has been greatly accepted until this day ${ }^{25}$ (cf. Brenko et al. 2001:191-211; Brenko 2005:107). From all the methods of education, like publishing health and educational books, brochures and leaflets, giving lectures and classes, the central method of promotion was education ${ }^{26}$ via film, a new and attractive medium.

In the 1920 s the social relation to the science was changed as well, which could have been seen in great optimism and thrust in scientific accomplishments and the hope that it would solve many questions related

25 The development of the precise rational and analytical methodology based on science and technology had a great role in discovering cure for a number of diseases that were considered to be untreatable (cf. Babel 2012:128).

26 Health education and health enlightenment were used as synonyms in the period between the wars, and terms health teaching and health propaganda were used with the same meaning, while the contemporary meaning of the phrase health education is much more narrow (cf. Dugac 2010:2). 
to public health and social problems. Science was given a significant role in the context of social progress and efficient health and social protection, which was to be available to all layers of the society, without exception (cf. Grmek 1958:94). The cooperation of the medical staff with the experts from other fields and the representatives of the local government was essential for achieving concrete results (Dugac 2005a:40). The slogan partner, but not patron was used to emphasize the importance of cooperation and active participation of those who were being educated, but also of the state on whose territory the programme was taking place (cf. Dugac 2005a:4). SPH took an important position in preventive public and health work and scientific education in Croatia and abroad. Social and medical ideas that were presented in the practice of SPH were completed through the presentation of good and bad examples of hygiene that were presented on film in rural areas (cf. Zebec et al. 1997:20). The Section of social medicine was one of the ten departments of the Hygiene Institute ${ }^{27}$ with the School of Public Health. It was very active in two aspects; lectures, posters, leaflets, films and exhibitions produced for the purposes of social medicine and education, and classes organized in the School of Public Health and in the villages (cf. Zebec et al. 1997:32). Within the Section of social medicine there were three Departments ${ }^{28}$, one of which was the Department for hygiene propaganda, whose task was to organise lectures with the help of their own education tools (books, brochures, leaflets, posters, films) (cf. ibid. 29). The School of Public Health had a wide range of activities, most popular of which were the films produced for the purposes of health education and classes that took place within the Rural University. Next to nurses, teachers and priests, sanitary and building engineers also had a great role in education, while experts from other professions participated in the process of creating and collecting health and advertising material: photographers and movie directors, cameramen and film editors, painters and illustrators, text writers, etc. (cf. Dugac 2010:38-41).

27 Hygiene Institute was the regional hygiene institution (cf. Zebec et al. 1997:20).

28 Other two departments of the Section of social medicine were the Department for the education of people and the Department for the study of folk pathology (cf. Zebec et al. 1997:29). 


\section{FROM GAVAZZI AND ŠTAMPAR TO ETHNOGRAPHIC FILM?}

Comprehensive and serious research could not have been conducted in the 1940 s, especially in the countries that were directly affected by the war. Investments in science were reduced to a minimum because the funds were redirected to military purposes and the film, as a relatively expensive method of work, was among the first that were left without the financial support of the state. Political situation was also extremely difficult. Nevertheless, SPH remained active during the war since recording was their basic activity for which they had available funds. Planned documentary films, whose function was primarily descriptive and informative, were made and the approach to the material was one of a travelogue or of health and education (cf. Gotthardi-Pavlovsky 2009:43-44).

After the war, in the beginning of 1950s, Gavazzi continued making short film records for the Ethnological Seminar. Four films were made, one of which was made by Gavazzi ( $O$ tatauiranju kod Banje Luke $^{29}$, 1952) (cf. Gotthardi-Pavlovsky 2009:51-52). In 1957 Gavazzi encouraged the foundation of the CIFE board ${ }^{30}$ (Comité international du film ethnographique / The International Committee on Ethnographic Films) for Yugoslavia, which became the $9^{\text {th }}$ national board of CIFE (cf. Majcen 1998b:166). As the president of the Yugoslav board of CIFE, Gavazzi was often invited to participate at various conferences of visual anthropology. Due to his engagement in many other scientific and professional areas, however, he did not devote enough time or attention to visual anthropology or ethnographic film in a theoretical sense, which is especially apparent in the lack of textual analysis of the mentioned sub-discipline. Nevertheless, according to the analysed materials, it is evident that he was informed about the works of numerous and then distinguished theoreticians of visual anthropology and ethnographic film (cf. Gotthardi-Pavlovsky 2009:61).

There was still no study of the methods of ethnographic film records in our country, nor the institutionalizing or positioning of ethnographic

\footnotetext{
29 On tattoo practices near Banja Luka, TN

30 The International Committee on Ethnographic Films (CIFE), founded by Jean Rouch in 1952.
} 
film and visual anthropology as a sub discipline, in the form it took place in USA. There was also no adequate scientific production which focused on ethnographic film recording. There are two short texts by Milovan Gavazzi from the 1960s - Etnografski film, njegovo značenje i primjene ${ }^{31}(1964)$ in which ethnographic film is seen as a "scientific document", whose value lies in the truthful recording of the phenomena that will thus remain recorded even when they cease to exist in the real life (cf. Gavazzi 1964:58 as cited in Ghottardi-Pavlovsky 2009:61). Gavazzi makes the distinction between ethnographic, i.e. factual film and ethnological, i.e. scientific film (Gavazzi 1964:62). He develops this idea in the other text, published around twenty years later in Glasnik magazine of the Slovenian Ethnological Society - $O$ nujnosti kategorizacije etnografsko-folklornih filmov ${ }^{32}$, where he makes a distinction between a documentary film, which presents a specific event, with no scientific purpose and document film, he sees as a "true scientific film, record done after a specific previous study and precise preparation of ethnographic and folklore content that is to be recorded" (similar criteria as that of Margaret Mead) and which is a sub category of research film. This document film would, in our case, be ethnographic and folklore document film (Gavazzi 1987:111-112), Gavazzi divides into: "1. Cinematographic and ethnographic folklore notes", fragments that do not present the completed or whole versions of the content, " 2 . General monographic ethnographic and folklore films", he further divides into "monographic local films" and "monographic theme films", and "3. Comparative research ethnological films", which consist of the selection of independent sequences from different films, monographic and film notes and which present and compare the same ethnographic and folklore material from different areas or people (ibid. 112-113).

Gavazzi was aware of the difference between film recording and expression. His idea of scientific research, however, was obviously based on the older concept that sees the teller and their culture as an object of research and does not comprehend the problem of the researcher's interpretation of

\footnotetext{
31 Ethnographic film, its meaning and application, TN

${ }^{32}$ About the importance of categorization of ethnographic and folklore films, TN
} 
the other culture with the equivalents from their own culture so he uses film as an objective method of recording where the researcher has no need to show or explain their position. Gavazzi does not think about the distortions that are done to the recorded subject matter by the camera and the researcher, i.e. he does not take into account the fact as inevitable as a part of the specific method of recording. Although Gavazzi saw Flaherty's and Rouch's films, which he claimed to have encouraged him in his own film efforts (cf. Križnar 1992:189 as cited in Ghottardi-Pavlovsky 2009:62), he did not apply anything that was specific for them in his work. Among other things, Gavazzi claims to be self-taught in film recording because no one focused on it at its beginnings, "only professionals we had no connection with." He also said that people used to welcome them cordially, regardless of the fact that they had a camera in their hand and that they were "partly prepared for the recording, which meant that our acquaintances at the village had prepared them" (HR-HDA-1029 [3]). This is a very important statement, by which Gavazzi confirms that the order of events that was to take place before the camera was arranged; prepared beforehand and constructed, which clearly shows that these films are not observational documentary films.

In his interview with Naško Križnar from 1991 he spoke about the film Jedan dan u turopoljskoj zadruzi ${ }^{33}$ (Chloupek, Gerasimov, 1933), reconstruction that was made within the photographic and film department of SPH. Gavazzi was allegedly present at the recording although he had had no duties. He said that it was an exceptional film that he had looked up to, although he knew that it was a reconstruction that was less appreciated in scientific circles, at least according to the strict rules made by IWF:

"Back then there was nothing like that anymore. But the costume and gestures and speech (it was actually a silent film); it was all so nicely reconstructed so that it could have been used as a document."

To Križnar's question of his opinion on reconstruction Gavazzi replied:

${ }^{33}$ One day in Turopolje village community, TN 
"If the reconstruction is completely truthful, which can be verified by ethnologists, sociologists and other assistants, it can be done. However, it has to be clearly stated in the film - reconstruction of... - it is important to indicate that it was a 'set' situation."

According to this answer we can conclude that Gavazzi's ideas did not lag behind the ideas of his international colleagues (HR-HDA-1029 [3]). The films of SPH were made as supplementary material used to promote the idea of social medicine to the inhabitants of rural and poor areas. In that context film was recognized as a cultural mediator and the way of communication between doctors and rural population. Next to health instructions it also contained social elements of the ambition to improve the material conditions of the village population by introducing the viewers to the way of life, ethnographic particularities and cultural monuments. The same films are today seen as the images of past times and they evoke different meaning that the one they had around 80 years ago. Multiple perspectives allow the realisation of different views of the film, but not taking clear positions or the one that are set beforehand and a priori. Therefore, the films of the School cannot be seen as the only and most accurate source of ethnographic data. In a contemporary context they represent only one of several possible images of a specific time, by presenting the then current political and economic situation, as well as the (power) relations between the village and the town. "Ethnographic film" is thus understood as the consequence of historical, political and cultural circumstances within which the films of SPH change their genre (from health and education to ethnographic film) and are given new interpretations, depending on the context within which they are observed and analysed again. In that perspective, we can observe the films of the $\mathrm{SPH}$ as the image that reflects the time that no longer exists, but which is close to the time when the films are made, as well as the one in which they become alive again. (cf. Urem 2015:55, 137, 179-80). 


\section{TOWARDS THE CONCLUSION}

Was there a professional cooperation between Milovan Gavazzi and Andrija Štampar? What was Gavazzi's attitude towards the films of the School of Public Health and their authors? Gavazzi was a contemporary of Stampar and other associates of the School and had his own attitude on what ethnographic films or records should look like. According to the aforementioned and the fact that he took a positivist view on films, he was probably not too interested in the films of the School nor did he consider them to be relevant sources of ethnographic data. It is also possible that health and educational basis of the films did not attract Gavazzi's interest. Although Gavazzi did not classify the films made by the School that had no health topic as ethnographic because they were set film scenes, neither scientific nor objective enough. Nevertheless, in the context of the film Jedan dan u turopljskoj zadruzi, as it was mentioned before, Križnar (cf. 1992:191) emphasizes that Gavazzi was very satisfied with the film and considered it to be an extremely successful reconstruction. Twenty seven years later, in 1960, he even sent the film to 2 Festival dei Popoli, festival of ethnographic film in Florence, where it won the Grand prix award (cf. Škrabalo1984:74-75). According to the studied material, there was no cooperation between Gavazzi and the employees of the School of Public Health ${ }^{34}$. Was the reason a different approach in making films? Unlike Gavazzi, the employees of the School often recorded films with a huge TV crew on the field. We can also ask ourselves how was it that Gavazzi was aware of the fact that he had to record alone. Ruby wrote about it around 40 years after Gavazzi's beginnings with the film medium when he discussed the criteria that had to be fulfilled in recording an ethnographic film. In his criteria Ruby (2000:267) mentioned the one according to which we can call a film ethnographic if it was made by

\footnotetext{
34 In the article Korespondencija Milovana Gavazzija u Hrvatskom državnom arhivu (Stipančević 2005) it is mentioned that Chloupek, Drago (1899-1963), doctor and film director, employee of the School of Public Health and the head of its Department for education and promotion, exchanged two letters with Milovan Gavazzi. The letters refer to the use of the fee received as the first award for the film Jedan dan u turopoljskoj zadruzi at the film festival Festival dei Popoli in Florence in 1959 (cf. HR-HDA-1029 [2]).
} 
an anthropologist or a person with a formal anthropological education. Gavazzi fulfilled the set scientific criteria in his approach the film and followed the world trends of the use of the film in science - on the one hand, the film that is recorded and collected for the services of saving ethnography and, on the other hand, a film that will distribute the saved knowledge through education.

As it was already mentioned and has become apparent, ethnographic films were not only made by anthropologists, ethnologists and ethnocineastes $^{35}$ but directors and documentary makers as well. However, it is questionable whether the supporters of Heider's and Ruby's visual anthropology would even classify the films made by those who were not anthropologists as ethnographic (cf. Borjan 2013:21-22). The problem of defining and classifying ethnographic film is obvious, i.e. the ephemerality, changeability and ambivalence of the definition considering the dominant theoretical paradigm. Gavazzi's concept of the film as ethnological and its documentary value for the purposes of scientific research and presentation and Štampar's use of the film as a means of health education are strikingly different. The point where the concepts, although different, do meet can be seen subsequently, in the time when the phrase ethnographic film is used as a self-explanatory concept. Historical, political, social and institutional frames of the production of Gavazzi's and Štampar's films point to the fact that the phrase ethnographic film should not be used lightly and uncritically. On the contrary, it has to be understood in the context and seen as an area where the terms film, documentary and ethnographic can be analysed.

35 The term used by Etami Borjan (2013) 


\section{REFERENCES}

BABEL, Krešimir. 2012. "Metafore zdravlja i bolesti u medicinskoj praksi”. Filozofska istraživanja, 32/1: 121-138.

BANKS, Marcus. 2001. Visual Methods in Social Research. London: SAGE Publications.

BIĆANIĆ, Rudolf. 1940. "Agrarna prenapučenost”. Gospodarska struktura Banovine Hrvatske, 3:147-148.

BORJAN, Etami. 2013. “Promišljanje tradicionalnog u etnografskom filmu. Reprezentacija, etika i autohtonost”. Etnološka tribina, 43/36:3-24.

BORJAN, Etami. 2013a. Drugi na filmu: etnografski film i autohtono filmsko stvaralaštvo. Zagreb: Hrvatski filmski savez.

BRENKO, Aida. 2005. "Praktičari narodne medicine”. Etnološka istraživanja, 1/10:103127.

BRENKO, Aida, Željko DUGAC, and Mirjana RANDIĆ. 2001. Narodna medicina. Zagreb: Etnografski muzej.

CHLOUPEK, Drago. 1939. "Problemi higijenske propagande”. Liječnički vjesnik, 61:15 -25 .

CLIFFORD, James. 1988. The Predicament of Culture: Twentieth-Century Ethnography, Literature, and Art. Cambridge, MA: Harvard University Press.

COOMBE, Rosemary J. 1991. "Encountering the Postmodern: New Directions in Cultural Anthropology". Canadian Review of Sociology and Anthropology, 28/2:188-205. DOI: 10.1111/j.1755-618X.1991.tb00151.x

CVETNIĆ, Slavko. 2009. Mraclin: kak je negda bilo. Mjestopisne i povijesne crtice. Mraclin: self-published.

DUGAC, Željko. 2005. “Zdravstveno prosvjećivanje protiv tuberkuloze u međuratnoj Hrvatskoj”. MEDICUS, 14/1:155-171.

DUGAC, Željko. 2005a. Protiv bolesti i neznanja. Rockefellerova fondacija u međuratnoj Jugoslaviji. Zagreb: Srednja Europa.

DUGAC, Željko. 2010. Kako biti čist $i$ zdrav: zdravstveno prosvjećivanje u međuratnoj Hrvatskoj. Zagreb: Srednja Europa.

DURINGTON, Matthew and Jay RUBY. 2011. "Ethnographic Film". In Made to Be Seen: Perspectives on the History of Visual Anthropology, ed. Marcus Banks and Jay Ruby. University of Chicago Press, 190-208.

EL GUINDI, Fadwa. 1998. "From Pictorializing to Visual Anthropology". In Handbook of Methods in Cultural Anthropology, ed. H. Russell Bernard. London: Sage Publications, 459-512.

ENGELBRECHT, Beate, ed. 2007. Memories of the Origins of Ethnographic Film. Frankfurt am Main: Peter Lang. 
GAVAZZI, Milovan. 1964. “Etnografski film, njegovo značenje i primjena”. Slovenski etnograf, 16/17:57-64.

GAVAZZI, Milovan. 1987. "O nujnosti kategorizacije etnografsko-folklornih filmov”. Glasnik SED, 27/3-4:111-114. Ljubljana: Slovensko etnološko društvo.

GOTTHARDI-PAVLOVSKY, Aleksej. 2009. Hrvatska etnografska audiovizualna produkcija u okviru svjetskih dostignuća, magistarski rad. Zagreb: Sveučilište u Zagrebu, Filozofski fakultet.

GRANDITS, Hannes. 2012. Obitelj i socijalne promjene u hrvatskim selima (18. - 20. stoljeće). Studije slučaja Bobovac i Lekenik. Zagreb: FF Press.

GRIMSHAW, Anna. 2001. The Ethnographer's Eye: Ways of Seeing in Anthropology. Cambridge: Cambridge University Press.

GRMEK, Mirko Dražen. 1958. “O životu i djelima Andrije Štampara”. Zdravstvene novine Škole narodnog zdravlja, 11/7:92-103.

HABERMAS, Jürgen. 1981. "Modernity Versus Post-Modernity”. New German Critique, 22:3-14. DOI: $10.2307 / 487859$

HEIDER, Karl. 1976 [2006]. Ethnographic Film. University of Texas Press.

KRIŽNAR, Naško. 1992. "Razgovor z Milovanom Gavazzijem”. Etnološka tribina, 15:187-200.

LASS, Andrew. 1988. "Romantic documents and political monuments: the meaningfulfillment of history in 19th century Czech nationalism". American Anthropologist, 15/3:456-471. DOI: 10.1525/ae.1988.15.3.02a00030

LEČEK, Suzana. 1995. “Između izvornog i novog - „Seljačka sloga“ do 1929. godine”. Etnološka tribina, 18:103-123.

MACDOUGALL, David. 1981. "A Need for Common Terms". SAVICOM Newsletter, Society for the Anthropology of Visual Communication, 9/1:5-6.

MACDOUGALL, David. 1998. Transcultural Cinema. Princeton University Press.

MAJCEN, Vjekoslav. 1995/1996. "Etnološki filmovi Milovana Gavazzija i hrvatski etnološki film u prvoj polovini 20. stoljeća”. Studia ethnologica Croatica, 7/8:121134.

MAJCEN, Vjekoslav. 1996. "Kulturološke i socijalne osnove filmova Škole narodnog zdravlja u svjetlu ideja braće Radić". Arhivski vjesnik, 39:127-138.

MAJCEN, Vjekoslav. 1998. "Hrvatski obrazovni film - I". Hrvatski filmski ljetopis, 13:159-179. Zagreb: Hrvatski filmski savez.

MAJCEN, Vjekoslav. 1998a. "Hrvatski obrazovni film - II”. Hrvatski filmski ljetopis, 14:140-167. Zagreb: Hrvatski filmski savez.

MAJCEN, Vjekoslav. 1998b. "Hrvatski obrazovni film - III". Hrvatski filmski ljetopis, 15:159-179. Zagreb: Hrvatski filmski savez. 
MILENKOVIĆ, Miloš. 2007. Istorija postmoderne antropologije. Teorija etnografije. Beograd: Srpski genealoški centar.

NICHOLS, Bill. 2001. Introduction to Documentary. Bloomington: Indiana University Press.

PICTON, Oliver. 2011. “Anthropologists Working 'at Home': On the Range of Subjects and Forms of Representation in Film, and What Makes These Ethnographic". Visual Anthropology, 24/5:421-436. DOI: 10.1080/08949468.2011.604596

PLETENAC, Tomislav. 1996. "Vidljivo i nevidljivo u etnografskom filmu - rani etnografski filmovi prof. Gavazzija”. In Etnološki film med tradicijo in vizijo, ed. Naško Križnar. Ljubljana: Založba ZRC, 133-141.

PULJAR D’ALESSIO, Sanja. 2002. “O etnografskom filmu u odnosu na etnografsko pismo". Narodna umjetnost, 39/2:33-51.

RIHTMAN-AUGUŠTIN, Dunja. 1978. "Folklor, folklorizam i suvremena publika". Etnološka tribina, 7-8/1:21-28.

RIHTMAN-AUGUŠTIN, Dunja. 1979. “Istraživanje folklora i kulturna praksa”. Narodna umjetnost, 16/1:9-19.

RIHTMAN-AUGUŠTIN, Dunja. 1992. "O konstrukciji tradicije u naše dane: rituali, simboli i konotacije vremena”. Narodna umjetnost, 29/1:25-42.

RUBY, Jay. 2000. Picturing Culture. Chicago: The University of Chicago Press.

SREMEC, Zlatko and Nikola, NIKOLIĆ. 1941. Hrvatsko selo i medicina. Zdravstveno politička rasprava. Zagreb: Zavod za proučavanje seljačkog i narodnog gospodarstva Gospodarske sloge.

STIPANČEVIĆ, Mario. 2005. "Korespondencija Milovana Gavazzija u Hrvatskom državnom arhivu". Arhivski vjesnik, 48:55-68.

ŠKRABALO, Ivo. 1984. Između publike i države. Povijest hrvatske kinematografije: 1896-1980. Zagreb: Znanje.

UREM, Sandra. 2015. Problematiziranje sintagme 'etnografski film' na primjeru filmova Škole narodnog zdravlja, doktorski rad. Sveučilište u Zagrebu, Filozofski fakultet.

ZEBEC, Mirna et al.1997. Škola narodnog zdravlja "Andrija Štampar": 70 godina rada na promicanju zdravlja hrvatskog puka. Zagreb: Gandalf.

http://fuliranje.com/zanimljivo/ (Accessed: 12 March 2014)

http://www.enciklopedija.hr/Natuknica.aspx?ID=41465 (Accessed: 12 March 2014) 


\section{ARCHIVE SOURCES}

$\mathrm{HDA}=$ Croatian State Archives

HR-HDA-1029 [1]. Hrvatski državni arhiv, Fond Milovan Gavazzi, Različite funkcije na Filozofskom fakultetu u Zagrebu, Milovan Gavazzi kao voditelj ili suradnik istraživačkih projekata Odsjeka za etnologiju Filozofskog fakulteta, Kt. 7. Izvještaj o snimanju etnografskih filmova, 1964. - 1983., 5 pages, typed.

HR-HDA-1029 [2]. Hrvatski državni arhiv, Fond Milovan Gavazzi, Stručni, znanstveni i znanstveno - publicistički rad, "Festival dei Popoli", Kt. 33. i 34. I. i II. Festival dei Popoli (Međunarodni festival etnografskog i sociološkog filma), Firenze, 14.-20. 12. 1959. i 12.-18. 12. 1960., 41 pages

HR-HDA-1029 [3]. Hrvatski državni arhiv, Fond Milovan Gavazzi, Stručni, znanstveni i znanstveno - publicistički rad, Tekstovi i članci Milovana Gavazzija (rukopisi, špalte, separati i sl.), Kt. 49, 6.3.2.59. Intervju Milovana Gavazzija vezan za etnografski film.

HR-HDA-1029 [4]. Hrvatski državni arhiv, Fond Milovan Gavazzi, Tekstovi drugih autora, Rukopisni i strojopisni koncepti, Kt. 96. "Vidljivo i nevidljivo u etnografskom filmu - rani etnografski filmovi prof. Gavazzija”, s.a., 5 pages, typed. 
